DCPAR1 IS REQUIRED FOR DEVELOPMENT AND CAROTENOID SYNTHESIS

Short title: DcPAR1, a key factor in carrot taproot development

Daniela Arias ${ }^{1}$, Angélica Ortega ${ }^{1}$, Christian González ${ }^{1}$, Luis Felipe Quiroz ${ }^{1}$, Jordi

7 Moreno-Romero ${ }^{2,3}$, Jaime F. Martínez-García ${ }^{2,3}$ and Claudia Stange ${ }^{1}$

$8{ }^{1}$ Centro de Biología Molecular Vegetal, Facultad de Ciencias, Universidad de Chile, 9 Chile.

$10{ }^{2}$ Centre for Research in Agricultural Genomics (CRAG), CSIC-IRTA-UAB-UB, 11 Barcelona, Spain;

$12{ }^{3}$ Institute for Plant Molecular and Cell Biology (IBMCP) CSIC-UPV, València, Spain.

14 Author contributions: C.S. conceived the research plans; C.S. and J.F.M-G. 15 supervised the experiments; D.A. and A.A performed the experiments; J. M-R, C.G 16 and L.F.Q. performed some experiments with D.A; J.F.M-G. provided technical 17 assistance to D.A.; C.S. designed the experiments and analyzed the data; C.S. 18 conceived the project and wrote the article with contributions of all the authors; C.S.

19 agrees to serve as the author responsible for contact and ensures communication.

21 One-sentence summary: DcPAR1 is a key factor for secondary root

22 development, plastid differentiation and carotenoid synthesis in carrot taproot 23 grown underground.

25 Funding: Chilean ANID Fondecyt Grant 1180747 (CS), Spanish MINECO- FEDER 26 grant BIO2017-85316-R to JFM-G, European Commission contract H2020-MCSA27 IF-2017 (proposal 797473) to JM-R. 


\section{Abstract}

35 Light stimulates carotenoid synthesis in plants during photomorphogenesis through 36 the expression of PHYTOENE SYNTHASE (PSY), a key gene in carotenoid 37 biosynthesis. The orange Daucus carota (carrot) synthesizes and accumulates 38 high amounts of carotenoids in the taproot that grows underground. Contrary to 39 other organs, light impairs carrot taproot development and represses the 40 expression of carotenogenic genes such as DCPSY1 and DCPSY2 reducing 41 carotenoid accumulation. By means of an RNA-seq, in previous analysis we 42 observed that carrot PHYTOCHROME RAPIDLY REGULATED 1 (DCPAR1) is 43 more expressed in the underground grown taproot respect to those grown in light. 44 PAR1 is a transcriptional cofactor with a negative role in the shade avoidance 45 syndrome regulation in Arabidopsis thaliana through the dimerization with 46 PHYTOCHROME INTERACTING FACTORs (PIFs), allowing a moderate synthesis 47 of carotenoids. Here we show that overexpressing AtPAR1 in carrot produces an 48 increment of carotenoids in taproots grown underground as well as higher DCPSY1 49 expression. The high identity of AtPAR1 and DcPAR1 let us to suggest a functional 50 role of DcPAR1 that was verified through the in vivo binding to AtPIF7 and the 51 overexpression in Arabidopsis, where it increments AtPSY expression and 52 carotenoid accumulation together with a photomorphogenic phenotype. Finally, 53 DCPAR1 antisense carrot lines presented a dramatic decrease in carotenoids 54 levels and in the relative expression of key carotenogenic genes as well as 55 impairment in taproot development. These results let us to propose that DcPAR1 is 56 a key factor for secondary root development, plastid differentiation and carotenoid 57 synthesis in carrot taproot grown underground.

59 Keywords: Carrot, PHYTOCHROME RAPIDLY REGULATED 1 (PAR1), 60 carotenoids, phytoene synthase (PSY), root development, plastid differentiation. 


\section{Introduction}

64 Light is an essential cue for plant development and growth since it is required for

65 photosynthesis and photomorphogenesis (Tripathi et al., 2019). In both processes,

66 the plastidial pigments chlorophylls and carotenoids fulfil crucial roles. Synthesis of

67 chlorophylls and carotenoids is strongly promoted by light (Stange and Flores,

68 2012). Carotenoids also provide yellow, orange and red colors to flowers, fruits and

69 some roots. These pigments are not only powerful antioxidant that protect plants

70 from photooxidative damage but also precursors of important compounds such as

71 the phytohormones strigolactones and abscisic acid (ABA) that affect plant

72 development (Hirschberg, 2001; Howitt and Pogson, 2006; Sandmann et al., 2006;

73 Rodríguez-Concepción, 2010; Ruyter-Spira et al., 2013; Sandmann, 2015;

74 Simpson et al., 2016a). The first enzyme in carotenoid synthesis and the most

75 regulated at the transcriptional and posttranscriptional level is phytoene synthase

76 (PSY) (Maass et al., 2009; Rodríguez-Villalón et al., 2009; Rosas-Saavedra and

77 Stange, 2016). Whereas in Arabidopsis thaliana this enzyme is encoded by the

78 AtPSY gene, in carrots (Daucus carota) it is encoded by two genes, DcPSY1 and

79 DCPSY2.

80 When seedlings germinate in the dark, they exhibit a pale yellow or rather whitish

81 color due to the lack of pigmentation (etiolated seedlings). In these conditions,

82 PHYTOCHROME INTERACTING FACTORs (PIFs) accumulate and repress

83 photomorphogenesis. PIFs are a subfamily of basic helix-loop-helix (bHLH)

84 transcription factors that act as central mediators in a variety of light-mediated

85 responses, including transitions from etiolated to de-etiolated seedlings and plants

86 responses to vegetation proximity (Leivar et al., 2009; Pham et al., 2018). As part

87 of their repressive role of the photomorphogenic development in the dark, PIFs

88 bind to AtPSY Light Responsive Elements (LREs, such as G-box), preventing their

89 expression and impeding the synthesis and accumulation of carotenoids in these

90 conditions (Toledo-Ortiz et al., 2010). Once the emerging seedlings perceive the

91 light, photomorphogenesis is triggered (de-etiolation), which results in inhibition of

92 stem elongation (e.g., hypocotyls or epicotyls), promotion of cotyledon or leaf 
93 expansion and promotion of chlorophyll and carotenoids synthesis, which result in

94 the acquisition of the characteristic green color of plants (Quail, 2002; Kami et al.,

95 2010; De Wit et al., 2016). Light perception is carried out by photoreceptors such

96 as phytochromes (PHYs), cryptochromes (CRYs) and phototropins (Kami et al.,

97 2010; Stange and Flores, 2012; De Wit et al., 2016; Quian-Ulloa and Stange 2021).

98 In particular, PHYs participate in the induction of the expression of key

99 carotenogenic genes such as PSY (Hirschberg, 2001; Bramley, 2002; Simkin et al.,

100 2003; Woitsch and Römer, 2003; Adams-Phillips et al., 2004; Giovannoni, 2004;

101 Rodriguez-Concepcion and Stange, 2013). During de-etiolation, the light activation

102 of PHYs triggers PIF phosphorylation, which are subsequently degraded by the

103 proteasome and/or inactivated, therefore making them unable to bind to LREs (Bae

104 and Choi, 2008; Shen et al., 2008; Shin et al., 2009; Toledo-Ortiz et al., 2010). This

105 results in a rapid de-repression of PSY gene expression and a burst in the

106 production of carotenoids in coordination with chlorophyll biosynthesis and

107 chloroplast development for an optimal transition to photosynthetic metabolism

108 (Toledo-Ortiz et al., 2010). In addition to repressing gene expression, PIFs also

109 promote the expression of dozens of genes in the dark that are also rapidly down-

110 regulated after seedling de-etiolation, such as $A$. thaliana PHYTOCHROME

111 RAPIDLY REGULATED 1 (AtPAR1), that encodes for a transcriptional cofactor of

112 the bHLH family. AtPAR1 physically interacts with PIFs, thus partially preventing

113 the binding of PIFs to LREs of photomorphogenic genes hence producing

114 intermediate phenotypes between dark- and light-grown plants regard pigment

115 synthesis and plant lenght (Bou-Torrent et al., 2015). A. thaliana lines that

116 overexpress AtPAR1 present an increase in total carotenoids in photosynthetic

117 tissues, an increment in AtPSY expression and an exacerbated photomorphogenic

118 phenotype shown as a reduced hypocotyl length (Roig-Villanova et al., 2007; Hao

119 et al., 2012; Zhou et al., 2014; Bou-Torrent et al., 2015).

120 Unlike other plants, orange carrots accumulate large amounts of carotenoids in its

121 underground and dark-grown taproots (Stange et al., 2008; Fuentes et al., 2012;

122 Rodriguez-Concepción and Stange, 2013). Surprisingly, root exposure to white

123 light $(\mathrm{W})$ causes a reduction in the expression of carotenogenic genes such as 
124 PSYS and LYCOPENE BETA-CYCLASES (LCYBS) and a decrease in carotenoid 125 levels (Fuentes et al., 2012; Llorente et al., 2017; Arias et al., 2020). Indeed, the 126 carrot root grown in $\mathrm{W}$ has a thinner and greener phenotype and presents an 127 enrichment of chloroplasts instead of carotenoid accumulating chromoplasts 128 (Fuentes et al., 2012). The expression profile between carrot taproot grown in W 129 and underground (dark-grown) was achieved and compared through an RNA-Seq 130 (Arias et al., 2020). This led us to identify several carrot genes related to 131 photomorphogenesis, such as DcPHYA, DcPHYB, and DcPAR1, whose transcripts 132 accumulated in the underground dark-grown taproot but was rapidly reduced in the 133 root when exposed to W (Arias et al., 2020).

134 In this work we aimed to functionally characterize DCPAR1 to determine its role in 135 photomorphogenesis and in carotenoid synthesis in Arabidopsis and carrot. We 136 showed that overexpression of AtPAR1 in transgenic carrot present higher levels of 137 carotenoids in taproots as well as higher DCPSY1 expression suggesting a key role 138 of the PAR1 in carrot carotenoid synthesis. The high similarity of AtPAR1 and 139 DcPAR1 let us to suggest a functional role of DcPAR1 that was verified through the 140 in vivo binding to AtPIF7 and overexpression in Arabidopsis. Most importantly, 141 DCPAR1 antisense carrot plants showed an impaired taproot development, plastid 142 differentiation and a dramatic decrease in both carotenoids levels and in the 143 relative expression of key carotenogenic genes. These led us to propose that 144 DcPAR1 is a transcriptional cofactor with a key role in the regulation of taproot 145 development and carotenoid synthesis in the carrot taproot grown underground. 
Carrot plants overexpressing AtPAR1 present higher carotenoid levels and an increment in DCPSY1 expression in the taproot grown underground

153 As a first approximation in order to determine if a functional PAR1 has an effect in 154 carotenoid synthesis in the carrot taproot, we overexpressed AtPAR1 in carrots.

155 During carrot transformation it trapped our attention that AtPAR1 embryos 156 presented an orange phenotype instead of the normal whitish coloration in WT 157 embryos (Figure 1A). This early observation suggested that AtPAR1 could promote 158 the synthesis of carotenoids in carrots in early stages of development. Next, four 159 adult plants (grown 4 months in the greenhouse), that overexpressed AtPAR1, 160 were selected, established as independent transgenic lines and subjected to 161 molecular and biochemical analysis (Figure 1B and 1C). Among the four lines, two 162 of them presented higher levels of transgene relative expression in the taproot 163 (OE1 and OE2, Figure 1B), which also showed an increment in DcPSY1 164 expression relative to WT taproots (Figure 1B). On the contrary, DcPSY2 showed a 165 decrease in the relative expression (Figure 1B) whereas the endogenous DcPAR1 166 was expressed at similar or reduced levels than WT plants (Supplemental Figure 167 1). Importantly, transgenic OE1 and OE2 lines, which have the highest expression 168 levels of AtPAR1 and DCPSY1, presented an average of 2.5 times more total 169 carotenoids in their taproots compared to WT plants $(919.6 \mu \mathrm{g} / \mathrm{g}$ DW and 796.1 $170 \mu \mathrm{g} / \mathrm{g} \mathrm{DW}$ of carotenoids, respectively) (Figure 1C). Moreover, both OE1 and OE2 171 lines present also higher $\beta$-carotene level (2.3 and 2.4 times more than WT roots)

172 and only the OE1 line has significantly higher levels of a-carotene in their taproots 173 (Figure 1C). These results suggest that AtPAR1 is positively regulating carotenoid 174 synthesis by promoting the expression of the DcPSY1, but not DcPSY2.

177 The effect of AtPAR1 overexpression on taproot DCPSY1 expression and 178 carotenoid levels suggests that the product of a carrot PAR1 homologue might 


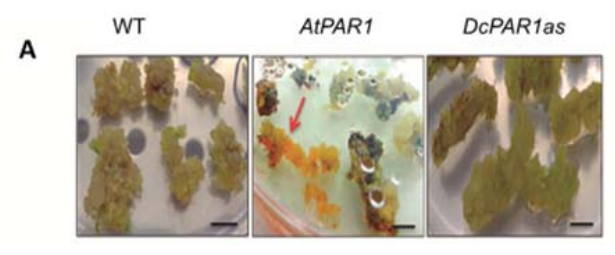

B
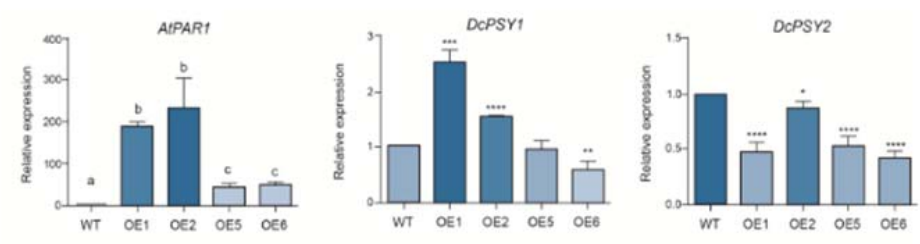

C
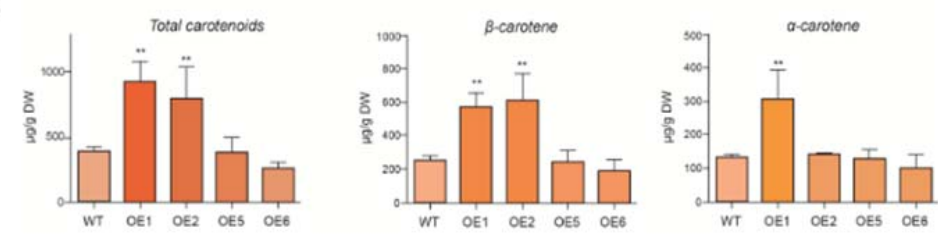

Figure 1. Molecular and biochemical analysis of AtPAR1 transgenic carrots. (A) In vitro regeneration of carrot transformant plants. Embryo regeneration stage is shown (18-20 weeks after explants transformation). The arrow indicates orange embryos that later gives rise to whole carrot plants in wild-type (WT), AtPAR1 (AtPAR1:GFP) and DcPAR1as. Scale bar: $5 \mathrm{~mm}$. (B) Real time expression of AtPAR1, DcPSY1 and DcPSY2 in transgenic (OE1, OE2, OE5 and OE6) and wild-type (WT) carrot taproots. Ubiquitin was used as housekeeping gene. (C) Total carotenoids, $\beta$-carotene and $\alpha$-carotene levels in transgenic (OE1, OE2, OE5 and OE6) and WT carrot taproots. Letters and asterisks indicate significant differences between WT and transgenic lines (one-way ANOVA analysis with Dunnet post-test; ${ }^{\cdots * *} p<0.0001,{ }^{\cdots *} p<0.001$, " $p<0.01, " p<0.1)$

179 have the same role as AtPAR1 in A. thaliana. Therefore, we identified contig 42760

180 (292 bp) obtained from the carrot transcriptome (Arias et al., 2020) which 181 presented a 98\% identity with AtPAR1 (At2g42870, Access No NM_129848.3) and 182 obtained the complete CDS sequence of DcPAR1 (Access No XM_017390696.1) 183 by searching in NCBI (Supplemental Figure 2). The complete CDS of DcPAR1 184 (363 bp) presents a 57.7\% nucleotide identity with AtPAR1 and 44\% identity at the 185 amino acid level (Figure 2A). We kept more attention to the bHLH domain 186 considering that the AtPAR1 protein presents a bHLH domain that allows it to 187 interact with PIFs and with itself but not to DNA (Galstyan et al., 2011, 2012). A 188 conserved domain search analysis was performed predicting a complete bHLH 189 sequence between residues 29 and 107 (Figure 2A). Comparing this predicted 190 sequence with AtPAR1 bHLH, DcPAR1 presented the key conserved Leu23 191 residue in Helix 1 (Figure 2B) and the conserved hydrophobic residues such as Val, 192 Ala, Leu and Ile in Helix 2, all of them important for dimer formation. In the basic 193 domain it presents an Asp, Glu and Lys at position 5, 9 and 13, respectively, that, 


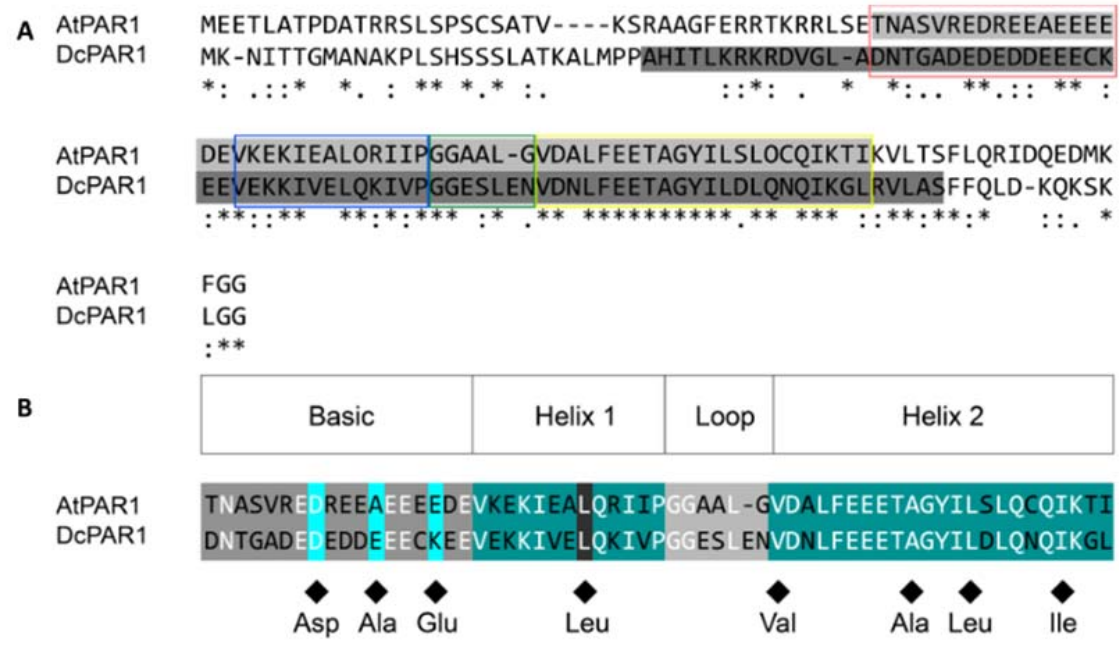

Figure 2. DcPAR1 and AtPAR1 protein alignment. (A) The predicted bHLH domains are highlighted in two shades of gray. The red box delimits the basic domains, and blue, green and yellow boxes mark the helix 1, the loop and the helix 2 subdomains, respectively. (B) Alignment of AtPAR1 and DcPAR1 bHLH domains. The upper boxes indicate the subdomain extensions based in Heim et al. (2003) and Roig-Villanova et al. (2007). Diamonds highlight residues 5, 9 and 13 (Asp, Glu and Lys, respectively), the conserved leucine residue at position 23 in helix 1 and additional conserved residues in helix 2. Different and identical amino acids are highlighted in each subdomain. All alignments were performed with Clustal Omega.

194 similar to AtPAR1 (Figure 2B), also differ from those (His5-Glu9-Arg13) required for 195 DNA binding (Heim et al., 2003). This sequence analysis suggests that DcPAR1 196 could be able to dimerize with other bHLH proteins but unable to bind DNA, 197 functionally acting as a transcriptional cofactor, as described for AtPAR1 (Galstyan 198 et al., 2011).

199 AtPIF7 has been shown to bind to PHYB (Leivar et al., 2008) and to have a role in 200 promoting Arabidopsis hypocotyls as a result of shade and warm temperature 201 treatments ( $\mathrm{Li}$ et al., 2012; Fiorucci et al., 2020). Considering that in $A$. thaliana a 202 functional AtPAR1 binds in vivo to PIFs and other bHLH proteins in the nucleus 203 (Hao et al., 2012; Cifuentes-Esquivel et al., 2013; Paulišić et al., 2021), we aimed 204 to determine whether the DcPAR1 protein is nuclear and capable of 205 heterodimerizing with other bHLH proteins. First, we observed that DcPAR1-GFP 206 presents nuclear localization in cells of Nicotiana benthamiana leaves 207 (Supplemental Figure 3). Next, we tested interaction of DcPAR1 to AtPIF7 in vivo 208 in N. benthamiana cells by bimolecular fluorescence complementation (BiFC). In 


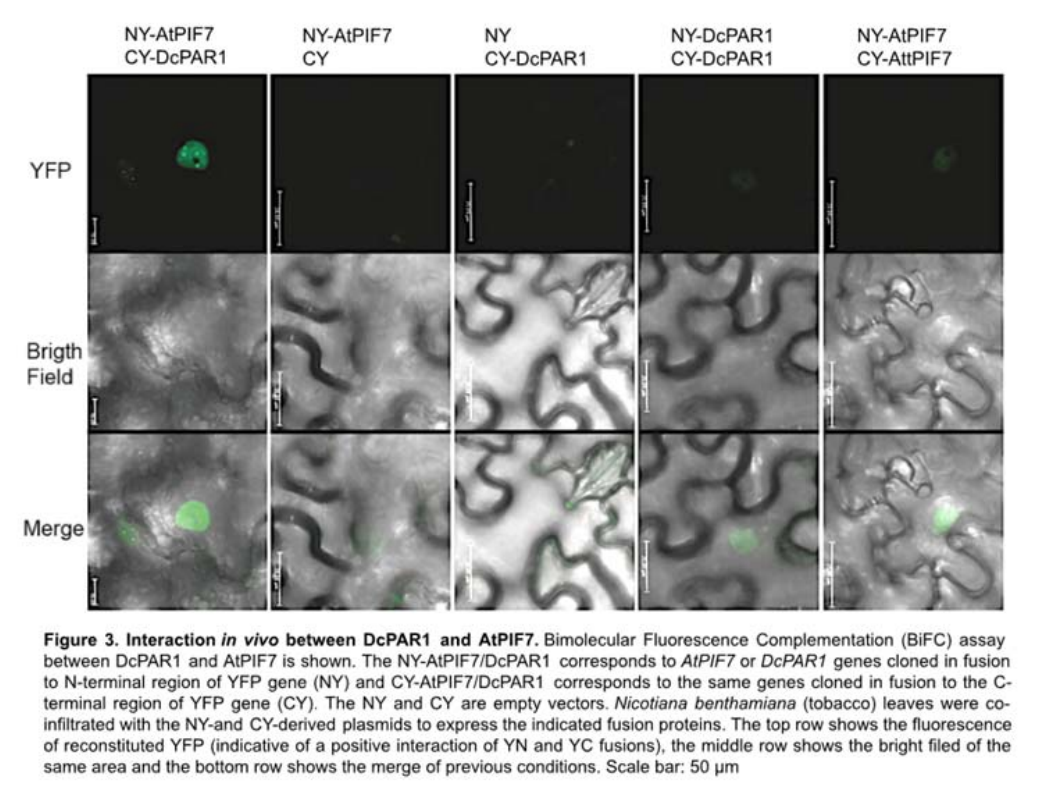

209 Figure 3 the reconstitution of YFP fluorescence is observed into the cell nucleus of

210 leaves co-agroinfiltrated with the $\mathrm{N}$-terminal part of the YELLOW

211 FLUORESCENCE PROTEIN (YFP, NY) fused to AtPIF7 (NY-AtPIF7) and the C-

212 terminal part of the YFP (CY) fused to DcPAR1 (CY-DcPAR1), thus demonstrating

213 that both proteins interact in vivo. Fluorescence is also detected in NY-DcPAR1

214 and CY-DcPAR1 co-agroinfiltrations (Figure 3), indicating that DcPAR1 can also

215 homodimerize as has been described for AtPAR1 (Bou-Torrent et al., 2015).

216 Together, these results suggested that DcPAR1 has the ability to dimerize with

217 itself and with PIFs, as it has been shown for AtPAR1.

219 Arabidopsis plants that express DCPAR1 present an increment in 220 carotenoids with a higher AtPSY expression and AtPSY protein abundance

222 Overexpression of AtPAR1 results in dwarf plants and increments in AtPSY 223 expression and carotenoid level in Arabidopsis (Roig-Villanova et al., 2007; Bou-

224 Torrent et al., 2015). We next overexpressed DcPAR1 in Arabidopsis to evaluate if

225 it provides similar phenotypes as AtPAR1. We obtained more than 20 independent 226 transgenic lines and selected four T3 transgenic lines that express DcPAR1 227 (Figure 4A) for further analysis that were done in two-week-old plants grown under 

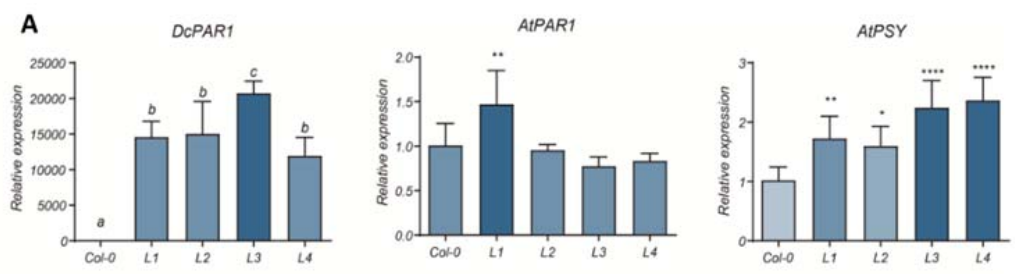

B
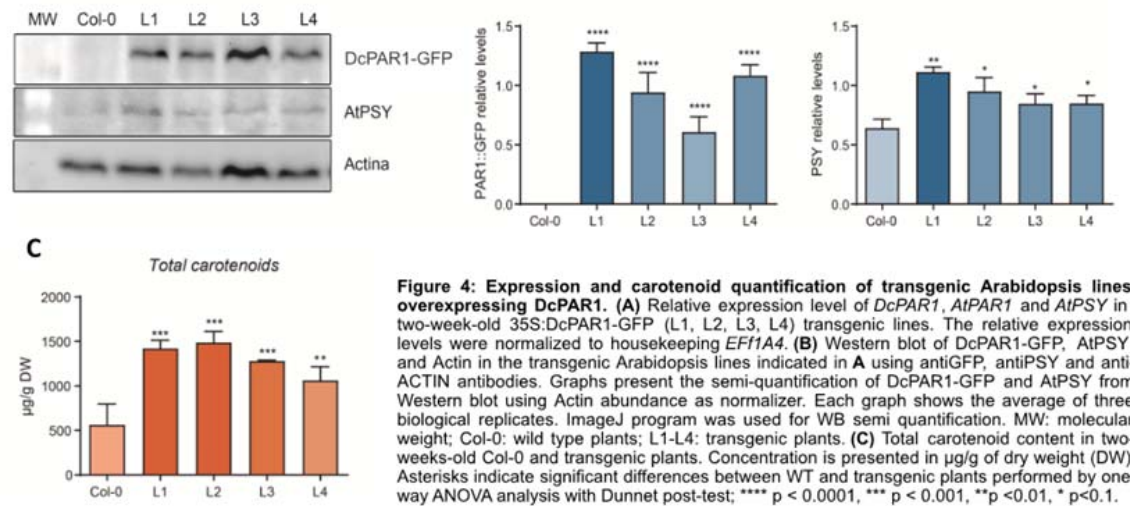

Figure 4: Expression and carotenoid quantification of transgenic Arabidopsis lines overexpressing DcPAR1. (A) Relative expression level of DcPAR1, AtPAR1 and AtPSY in
two-week-old 35S:DcPAR1-GFP (L1, L2, L3, L4) transgenic lines. The relative expression levels were normalized to housekeeping EFF1A4. (B) Western blot of DcPAR1-GFP, AtPSY and Actin in the transgenic Arabidopsis lines indicated in A using antiGFP, antiPSY and antiACTIN antibodies. Graphs present the semi-quantification of DCPAR1-GFP and AtPSY from Western blot using Actin abundance as normalizer. Each graph shows the average of three biological replicates. ImageJ program was used for WB semi quantification. MW: molecular weight; Col-0: wild type plants; L1-L4: transgenic plants. (C) Total carotenoid content in twoWeeks-old Col-0 and transgenic plants. Concentration is presented in $\mu g / g$ ol dry weight (DW) Asterisks indicate significant differences between WT and transgenic plants performed by one-

$228 \mathrm{~W}$ (long-day photoperiod). The relative expression of the endogenous AtPAR1 was

229 not significantly affected in the transgenic lines except for $L 1$, which presented a higher expression level than the wild-type line (Col-0) (Figure 4A). Importantly, all

231 transgenic lines presented a significant increase in AtPSY relative expression

232 (Figure 4A), as in AtPAR1 overexpressing lines (Bou-Torrent et al., 2015). The 233 increase in the relative expression of AtPSY was accompanied by an increase in

234 the abundance of PSY protein in all transgenic lines (Figure 4B, Supplemental 235 Figure 4 shows coomassie blue staining as control) and an increment in total 236 carotenoids compared to Col-0 (Figure 4C) suggesting that DCPAR1 positively 237 regulates the expression of AtPSY and thus increasing carotenoids content in 238 Arabidopsis.

239 To determine if DcPAR1 also affects elongation, we assessed phenotypic analysis 240 in two-week- and 1.5-month-old transgenic lines. In two-week-old seedlings, 241 transgenic lines presented a reduced length in hypocotyl, cotyledons and primary 242 leaves length (Supplemental Figure 5) similar to that reported for Arabidopsis 243 AtPAR1 overexpressing lines (Roig-Villanova et al., 2007; Hao et al., 2012; Zhou et 244 al., 2014; Bou-Torrent et al., 2015). Moreover, all transgenic lines present a dwarf 245 phenotype (Figure 5A) with a significant reduced stem height and silique length 246 (Figure 5B) at the mature stage. These results suggest that the DcPAR1 is 
A

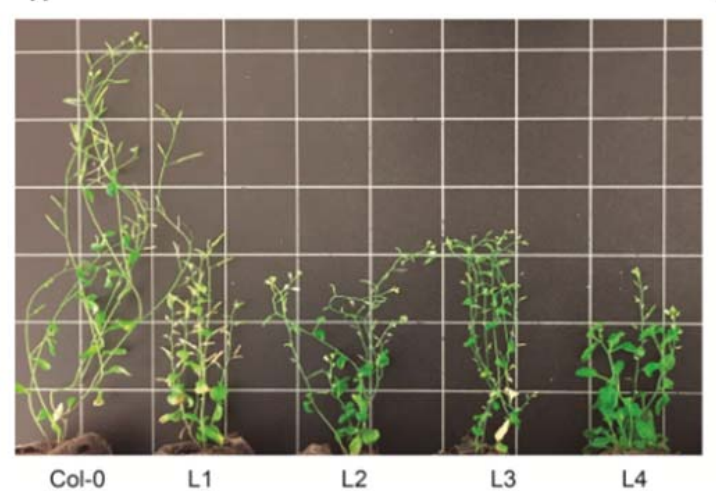

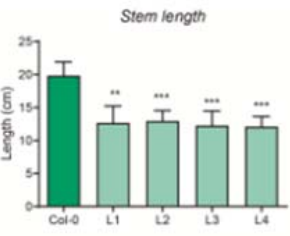

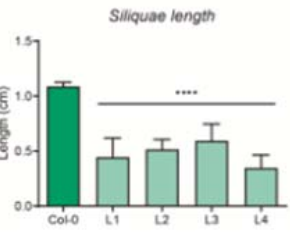

Figure 5: Phenotype of mature transgenic Arabidopsis lines overexpressing DcPAR1. (A) Picture showing the length and phenotype of representative six-weeks-old plants of Col-0 and T3 transgenic lines. (B) Stem and (C) Silique length of six-week-old Col-0 and T3 transgenic plants. Each value is the mean \pm SE/SD of 5 plants each and using Image J program. Asterisks indicate significant differences between WT and transgenic plants performed by one-way ANOVA analysis with Dunnet post-test; ${ }^{* * * *} p<0.0001,{ }^{* *} p<0.001,{ }^{*} p<0.01,{ }^{*} p<0.1$.

247 functional in vivo in promoting carotenoid synthesis and inhibiting growth in $A$. 248 thaliana.

250 Repression of DcPAR1 expression affects carrot taproots growth, carotenoid 251 composition and carotenogenic gene expression

253 The next step was to evaluate the role of DcPAR1 in carrot. For this, transgenic 254 antisense carrot plants for DCPAR1 were generated. During in vitro regeneration 255 process of DcPAR1 antisense plants (DcPAR1as) no phenotypic differences were 256 observed respect to WT embryogenesis (Figure 1A). Eleven mature plants were 257 obtained, and the molecular analysis confirmed that ten of them were transgenic 258 (Supplemental Figure 6). Four transgenic lines were selected for further molecular 259 and biochemical analysis. As is shown in Figure 6A, all transgenic lines presented 260 a dramatic reduction between $80 \%$ and $99 \%$ in the DCPAR1 expression and a 261 drastic reduction in the taproot secondary growth at the mature stage, as shown for 

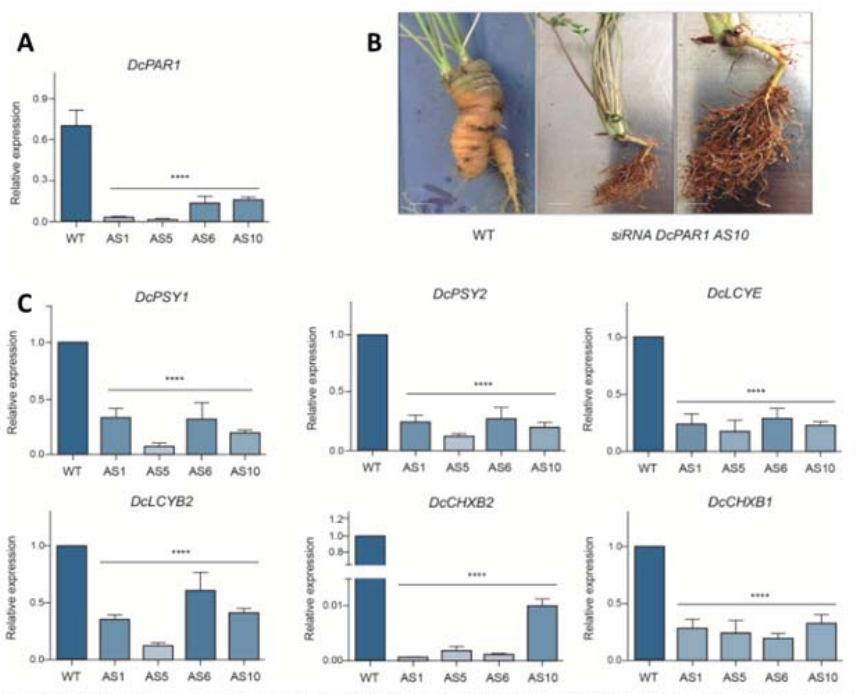

Figure 6: Phenotype and expression analysis of four-months-old DcPAR1as transgenic carrot taproots. (A) Relative expression level of DCPAR1 in AS1, AS5, AS6 and AS10 transgenics lines. (B) Representative phenotype of a WT and a DCPAR1as transgenic carrot root (line AS10) grown four months underground after transplanting. Bar: $1 \mathrm{~cm}$. (C) Relative expression level of DcPSY1, DcPSY2, DCLCYB2, D LCCYE DcCHXB1 and DcCHXB2. The relative expression was carried out in triplicate (two technical replicas each) and normalized to the housekeeping Ubiquitin gene. WT was used as calibrator. Asterisks indicate significant differences between transgenic lines and WT plant determined by one-way ANOVA analysis with Dunnet post-test; ${ }^{\cdots}{ }_{p}<0.0001, \cdots p<0.001, " * p<0.01, " p<0.1$

262 line AS10 (Figure 6B). The taproots of a four-month-old representative line that

263 grew underground was considerably smaller and thinner than WT taproots of the 264 same age and grown under the same conditions. The average mass of the 265 transgenic roots did not exceed $400 \mathrm{mg}$ while the average mass of a four-month266 old WT carrot taproot can weigh up to $7 \mathrm{~g}$ (Figure 6B). In addition, the roots were 267 pale suggesting that a significant reduction in carotenoid levels might have 268 occurred (Figure 6B). In addition, expression of key genes required for carotenoid 269 synthesis, DCPSY1, DCPSY2, DCLCYE, DCLCYB2, DCCHXB1 and DCCHXB2, was 270 significantly lower in all silenced lines relative to the WT, showing a reduction 271 between $40 \%$ and 99\% (Figure 6C). Moreover, a 50\%-80\% decrease in total 272 carotenoid levels in all silenced lines was also obtained (Figure 7A). Likewise, all 273 the transgenic lines showed a 4- to 60-fold decrease in a-carotene and 4- to 58274 fold in $\beta$-carotene (Figure 7B). However, an unexpected 6- to 15-fold increase in 275 lutein levels was obtained (Figure 7B). This pigment does not normally accumulate 276 in the orange carrot taproot that grows underground but in photosynthetic tissues 277 and in the WT carrot roots that grow exposed to light (Fuentes et al., 2012).

278 With the purpose of verifying that the taproot phenotype in silenced plants 279 persisted in time, the plants were grown four additional months underground in the 280 greenhouse (except the AS10 line that could not be maintained because it was 


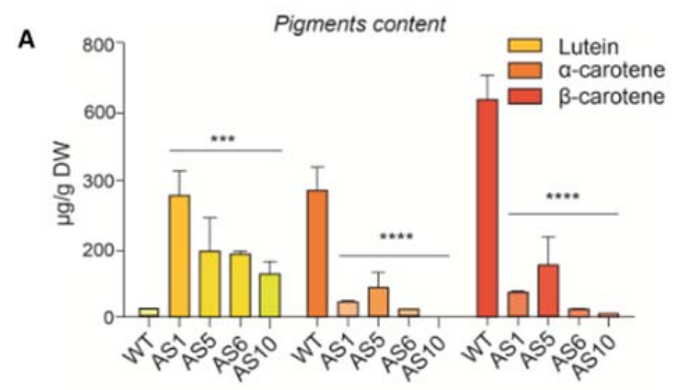

B

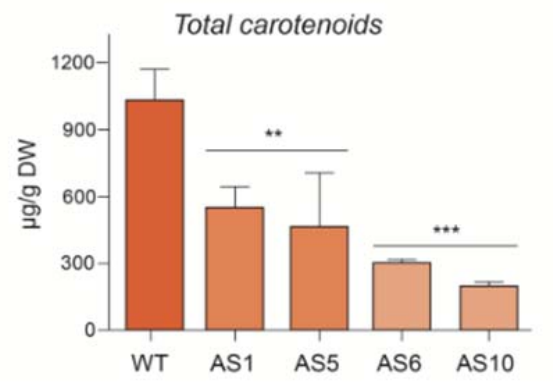

\begin{abstract}
Figure 7: Total and individual carotenoid content in four-month-old DcPAR1as carrot taproots. (A) lutein, $\alpha$-carotene and $\beta$-carotene levels was determined by HPLC-RP and (B) total carotenoids were quantified in a spectrophotometer at $474 \mathrm{~nm}$. The pigment content is indicated in $\mu \mathrm{g} / \mathrm{g}$ of dry weight (DW) and was measured in triplicate. Asterisks indicate significant differences between transgenic lines and WT plant determined by one-way ANOVA analysis with Dunnet post-test; ${ }^{* * *} p<0.0001,{ }^{\cdots *} p<0.001,{ }^{* *} p$ $<0.01,{ }^{*} p<0.1$
\end{abstract}

281 harvested and could not be recovered). We observed that, although the size of 282 transgenic roots increased respect to the four months, they were still smaller and 283 thinner than the WT taproots and presented a greenish coloration in the external 284 part of the taproot and a yellowish coloration in the taproot centre (Figure 8A). The 285 relative expression level of DCPAR1 in 8-months transgenic lines kept reduced 286 between $60 \%$ to $75 \%$ (Figure $8 \mathrm{~A}$ ). Likewise, the relative expression of the 287 carotenogenic genes in transgenic lines were still lower than in WT plants (Figure 288 8B), confirming that DcPAR1 indirectly regulates the expression of carotenogenic 289 genes in carrot root.

290 Carotenoids and chlorophylls quantification showed that DcPAR1as lines 291 presented 2.4-fold fewer total carotenoids (Figure 9A) and an increment of 3-5 to 8292 fold in chlorophyll $a$ and b reaching 100-250 $\mu \mathrm{g} / \mathrm{g}$ DW (Figure 9B), suggesting that 293 the absence of PAR1 leads to chloroplast instead of chromoplasts differentiation. 294 Likewise, transgenic antisense plants present a 3.5 to 14 -fold reduction in $\alpha$ 295 carotene and 3 to 9- fold reduction in $\beta$-carotene levels respect to WT plants. As in 


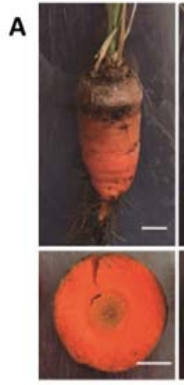

WT
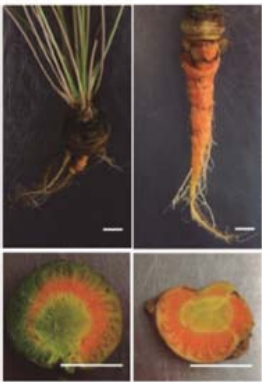

AS1

AS5

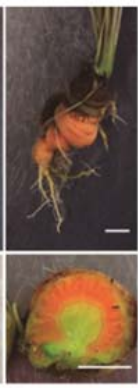

AS6

B

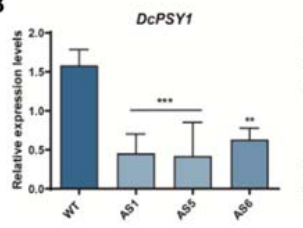

DCPSY2
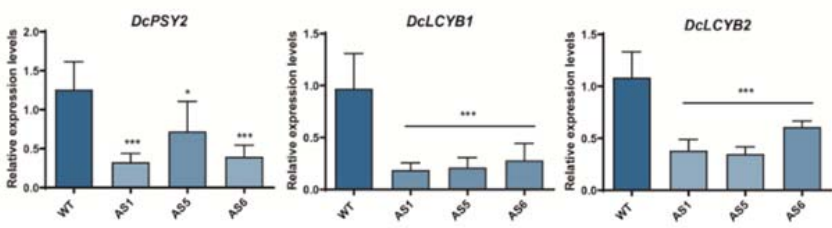

Figure 8: Phenotype and expression analysis of eights-months-old DcPAR1as transgenic carrot taproots. (A) Representative phenotype of carrot taproots of a WT and AS1, AS5 and AS6 DcPAR1as transgenic plants grown eight months underground after transplanting (line AS10 was harvested at four months and not shown in here). Bar: $1 \mathrm{~cm}$. Graph in the right shows the relative expression level of DcPAR1 in the indicated lines. (B) Relative expression level of DcPSY1, DcPSY2, DCLCYB2, DCLCYE, DCCHXB1 and DcCHXB2. Relative expression was carried out in triplicate (two technical replicas each) and normalized to the housekeeping Ubiquitin gene. Asterisks indicate significant differences between transgenic lines and WT plant determined by one-way ANOVA analysis with Dunnet post-test; $\cdots p<0.0001,{ }^{* *} p<0.001,{ }^{*} p<0.01,{ }^{*} p<0.1$

296 younger taproots, a significant increment in lutein was also observed, which 297 reached up to $200-250 \mu \mathrm{g} / \mathrm{g}$ DW (compared to $30 \mu \mathrm{g} / \mathrm{g}$ DW in WT) (Figure 9C), 298 thus explaining the yellowish coloration of antisense transgenic taproots respect to 299 the orange pigmentation of WT (Figure 8A). Taking all the results together, we

300 suggest that DCPAR1 is a functional cofactor that has an important regulatory role 301 not only in carotenoid synthesis in carrot taproot that grows underground, but also 302 in secondary taproot development and plastid differentiation. 


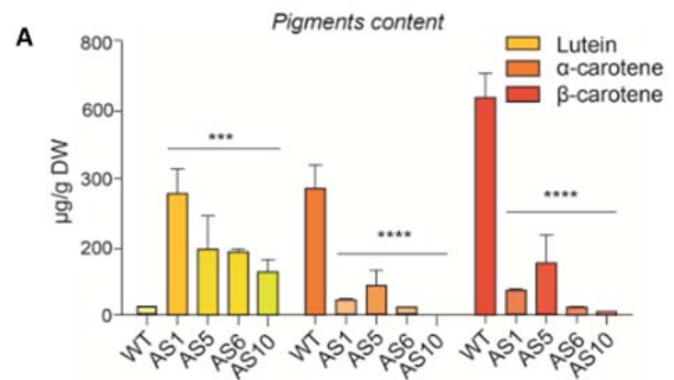

B

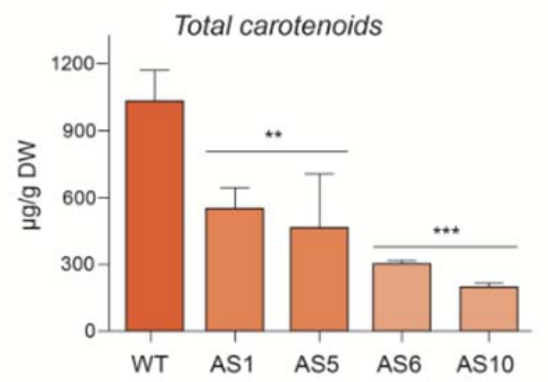

\begin{abstract}
Figure 7: Total and individual carotenoid content in four-month-old DcPAR1as carrot taproots. (A) lutein, $\alpha$-carotene and $\beta$-carotene levels was determined by HPLC-RP and (B) total carotenoids were quantified in a spectrophotometer at $474 \mathrm{~nm}$. The pigment content is indicated in $\mu \mathrm{g} / \mathrm{g}$ of dry weight (DW) and was measured in triplicate. Asterisks indicate significant differences between transgenic lines and WT plant determined by one-way ANOVA analysis with Dunnet post-test; ${ }^{* * *} p<0.0001,{ }^{\cdots *} p<0.001,{ }^{* *} p$ $<0.01,{ }^{*} p<0.1$
\end{abstract}

\title{
312 Discussion
}

314 DCPAR1 boosts carotenoid synthesis and promotes a photomorphogenic 315 phenotype in Arabidopsis

317 Carotenoid biosynthesis regulation in plants has been extensively studied.

318 Although there is much information about how this process is regulated by several

319 factors, there is still much to explore especially respect to how light regulates this process in plant organs that normally grow with no direct W, such as roots (Stanley

321 and Yuan, 2019; Quian-Ulloa and Stange, 2021). With the purpose to understand

322 how carotenoids are synthesized in orange carrot taproot, we compared through

323 RNAseq the expression profile of carrot roots that grew in $\mathrm{W}$ respect to those that

324 grew underground (Arias et al., 2020). We identified several photomorphogenic 325 genes that were upregulated in the underground condition and among them DcPAR1, DcPHYA and DcPIF4 presented twice as much expression level in 
327 darkness as in the root that grew in light (Arias et al., 2020). PAR1 is a recognized

328 negative regulator factor in the shade avoidance syndrome (SAS) and a positive

329 factors during seedling de-etiolation in Arabidopsis (Roig-Villanova et al., 2007;

330 Hao et al., 2012; Zhou et al., 2014). In shade, the expression of PAR1, PAR2 and

331 the LONG HYPOCOTYL IN FAR RED 1 (HFR1) is induced, factors that encode

332 transcriptional bHLH cofactors that participate in the compensation of excessive

333 hypocotyl elongation during SAS (Roig-Villanova et al., 2007; Bou-Torrent et al.,

334 2008; Hao et al., 2012; Zhou et al., 2014). From these factors, PAR1 interacts with

335 several bHLH proteins that act as positive regulators of SAS such as BEEs, BIMs

336 and PIFs by partially preventing the binding of these transcription factors to LREs

337 of photomorphogenic genes (Roig-Villanova et al., 2006; Cifuentes-Esquivel et al.,

338 2013; Ballaré and Pierik, 2017; Roig-Villanova et al., 2007; Hao et al., 2012;

339 Stange and Flores, 2012; Zhou et al., 2014; Bou-Torrent et al., 2015; Fernández-

340 Milmanda and Ballaré, 2021; Quian-Ulloa and Stange, 2021). Importantly, PAR1

341 promotes PSY expression under shade (Bou-Torrent et al., 2015) and, of the

342 positive SAS regulators BEEs, BIMs and PIFs, only PIFs participate in repressing

343 PSY expression and carotenoid synthesis in the shade (Toledo-Ortiz et al., 2010).

344 PIFs remain stable in the shade condition and bind to the LRE motifs (Lorrain et

345 al., 2008; Hornitschek et al., 2012).

346 AtPAR1 is an nuclear and atypical bHLH, presents a functional HLH protein

347 domain, but it lacks a functional DNA-binding domain, so its regulatory function is

348 performed through the dimerization with PIFs transcription factors. To date the

349 direct interaction between AtPAR1 and AtPIF4 and AtPIF1 has been shown (Roig-

350 Villanova et al., 2007; Hao et al., 2012; Bou-Torrent et al., 2015).

351 Our bioinformatic analysis indicated that DcPAR1 has a similar structural pattern to 352 AtPAR1, especially at the bHLH domain, suggesting that it could fulfill similar

353 functions. Importantly, the key amino acids at the basic domain that determines the 354 binding to DNA are also replaced by similar amino acids that are present in 355 AtPAR1 (Heim et al., 2003, Figure 2B). Likewise, the essential amino acid that 356 determine the protein-protein interaction are still conserved in DcPAR1 (Heim et 357 al., 2003, Figure 2B) which in functionality terms allows DcPAR1 to interact with 
358 other bHLH proteins, such as itself and AtPIF7 (Figure 3), an essential 359 characteristic for a functional PAR1.

360 AtPAR1 interacts with AtPIF1, and consequently induces the expression of AtPSY, 361 thus increasing the content of carotenoids together with the promotion of a 362 photomorphogenic phenotype (Roig-Villanova et al., 2007; Bou-Torrent et al., 363 2015). Interestingly, Arabidopsis plants overexpressing DCPAR1-GFP and grown in $364 \mathrm{~W}$, presented a stable accumulation of DcPAR1-GFP, suggesting that it is stable in $365 \mathrm{~W}$, similarly to AtPAR1 that is stable in low and high R:FR, but not in the dark 366 (Zhou et al., 2014). The higher DcPAR1-GFP accumulation correlates with an 367 increase in AtPSY relative expression levels and in PSY protein with a final rise in 368 total carotenoids (Figure 4C), which strongly suggest a positive role of DcPAR1 on 369 carotenoids synthesis in Arabidopsis. Indeed, the expression of the endogenous 370 AtPAR1 was not affected suggesting that PAR1 does not induce its own 371 expression in Arabidopsis. It remains to be elucidated whether the DcPAR1 protein 372 would be promoting AtPSY transcription through binding exclusively to PIF-type 373 transcription factors or if there are other transcription factors that may be involved 374 in this process, such as BEEs and BIMs (Cifuentes-Esquivel et al., 2013).

375 Moreover, according to the dwarf phenotype of Arabidopsis lines overexpressing 376 AtPAR1 (Roig-Villanova et al., 2007), 2 weeks-old DcPAR1 transgenic lines

377 presented several characteristics of a pronounced photomorphogenic phenotype 378 (Supplementary Figure 5) that remains until 1.5 months (Figure 5). Given these 379 results we strongly suggest that DCPAR1 and AtPAR1 are orthologs.

DCPAR1 positively regulates carotenoid synthesis and plastid differentiation 382 in carrot taproot

384 Knowing that AtPAR1 positively regulates the carotenoids synthesis in Arabidopsis 385 photosynthetic tissue (Roig-Villanova et al., 2007; Bou-Torrent et al., 2015) it 386 seemed a good starting strategy to visualize the in vivo role of a functional PAR1 in 387 carotenoids synthesis in carrot taproot. 
388 Carrot AtPAR1-GFP lines with the highest transgene expression (OE1 and OE2)

389 presented a significant increment in the relative expression levels of DcPSY1, but 390 not in DCPSY2 and DCPAR1, in correlation to an increase in carotenoid levels in 391 the taproot of mature carrots (Figure 1), suggesting that AtPAR1:GFP is sufficient

392 to produce the carotenoid increment in these lines. Interestingly, the transgenic 393 lines with the lower transgene expression level (OE5 and OE6), produced a 394 significant reduction in DCPSY1 (except for OE5), DCPSY2 and DcPAR1 395 expression but without affecting the level of carotenoids, which remains similar to 396 the WT. The decrease in the relative expression of DcPAR1 may be an 397 endogenous compensation mechanism leading to speculate that AtPAR1 may 398 regulate the expression of its ortholog gene in carrot. Given these results, we 399 suggest a positive regulation of AtPAR1 on DCPSY1 and not on DcPSY2 and that 400 the effect generated is due to the expression of AtPAR1 and not of the 401 endogenous gene.

402 The regulation of AtPAR1 on the different DcPSY paralogs may depend on the 403 transcription factors that bind to their promoters that can be regulated by AtPAR1. 404 It could be possible that AtPAR1 dimerizes to some endogenous carrot PIFs that 405 bind preferably to DcPSY1 than to DcPSY2 promoter, and the higher AtPAR1 406 abundance may recruit this type of PIFs preventing their binding to DCPSY1 407 promoter. Indeed, light-responsive elements (LRE) are located in the DcPSY1 and 408 DCPSY2 promoters (Simpson et al., 2018). It may be interesting to determine 409 which transcription factors directly bind to the promoters of DCPSY1 and DCPSY2 410 in carrots. Since DcPSY2 is mostly induced by salt stress and ABA and that AREB 411 transcription factors are able to bind to DCPSY2 promoter (Simpson et al., 2018), 412 we suggest that DCPSY2, and not DCPSY1, is induced under abiotic stress 413 (Simpson et al., 2018). It remains to be determined whether DcPSY1 could be 414 most associated to carotenoid synthesis during taproot development. On the other 415 hand, in transgenic carrots that express AtDXS (a gene that participates in the 416 synthesis of the metabolic precursors for carotenoids) an increase in carotenoid 417 levels was observed also in correlation to an increase in the expression of DcPSY1 
418 and DcPSY2 (Simpson et al., 2016b) suggesting that both genes determine the

419 levels of carotenoids in carrot taproots.

420 Likewise, the post-transcriptional gene silencing of DCPAR1 in carrots is a better

421 strategy to determine the role of the endogenous gene in carrots. DcPAR1

422 antisense had important consequences on the carotenoid levels (Figure 7 and 9),

423 which decrease significantly in correlation to a decrease in the expression of all

424 carotenogenic genes analyzed, including both, DCPSY1 and DcPSY2 (Figure 6

425 and 8). Similar results were reported in DCLCYB1 antisense carrots (Moreno et al.,

426 2013), where a decrease of $40-80 \%$ in total carotenoid levels together with a

427 decrease in the expression levels of DCPSY1 and DCPSY2 was observed (Moreno

428 et al., 2013). Moreover, DCPAR1 antisense lines showed a dramatic reduction in

429 the expression on all carotenogenic genes evaluated, in a direct or indirect

430 manner. Possibly, DcPAR1 has the ability to bind to PIFs or other unknown

431 transcription factors some of which would directly down or upregulate DCPSY1,

432 DCPSY2, DCLCYB1, DCLCYE, DcCBHX1 and/or DcCBHX2. It is also possible that

433 DcPAR1-DcPIFs complex exerts a direct regulation upon DcPSYs and the

434 activation of them has a direct impact on the other genes in the pathway. To

435 establish a more in-depth explanation in this regard, it is necessary to determine

436 which other factors, in addition to PIFs, are binding to PAR1 in carrots during

437 development and which transcription factors bind to promoters of carotenogenic

438 genes, inducing their expression. In Arabidopsis, ELONGATED HYPOCOTYL 5

439 (HY5) binds to PIFs and also competes with PIFs for binding to LRE, promoting

440 PSY expression and inducing the differentiation of etioplasts into chloroplasts with

441 an increment in carotenoids and chlorophylls in plants (Von Lintig et al., 1997;

442 Ronen et al., 1999; Woitsch and Römer, 2003; Toledo-Ortiz et al., 2010). It has

443 been proposed that there would be a genetic interaction between AtPAR1 and

444 AtHY5 because double antisense-PARs/hy5 mutants present a more elongated

445 hypocotyl than simple mutants (Zhou et al., 2014). Therefore, HY5 role in PAR1

446 antisense lines could be explored. Nevertheless, these results support the

447 hypothesis that DcPAR1 would be a positive regulator of carotenoid synthesis in 448 carrot taproot. 
449 Carrot DcPAR1as lines produce a significant increment in lutein (in four- and eight-

450 months old carrot taproots) similar to WT carrot roots grown in light, but absent in

451 taproots grown underground (Fuentes et al., 2012; Arias et al., 2020). Most

452 confusing is that $D c C H X B 1$ and $D c C H X B 2$, involved in lutein synthesis are deeply

453 down regulated (Figure 6C), suggesting that the enzymes may be stabilized by an

454 unknown mechanism.

455 In addition, DcPAR1 antisense lines present an increase in chlorophylls (in eight456 months old carrot taproots) that are normally absent in WT taproots, suggesting 457 that DcPAR1 not only is required for carotenoid synthesis or accumulation but also 458 in chromoplast differentiation. Indeed, DcPAR1 antisense lines present 459 chlorophylls as the WT roots that were grown in W (Fuentes et al., 2012) in which 460 DCPAR1 expression is lower than in the taproot grown underground (Arias et al., 461 2020).

DCPAR1 positively regulates carrot taproot development

468 It has been shown that the accumulation of carotenoids in carrot roots is 469 genetically associated to a homologue of the Arabidopsis PSEUDO-ETIOLATION 470 IN LIGHT (PEL) gene (lorizzo et al., 2016). PEL presumably acts as a repressor of 471 photomorphogenesis. Carrot varieties with a loss-of-function allele of the PEL gene 472 accumulate carotenoids in the root, suggesting that high pigment contents might 473 result from a derepressed development of carotenoid-accumulating plastids (i.e., 474 chloroplasts in the light but chromoplasts in the dark) (Llorente et al., 2017). Our 475 results support this possibility and go further in proposing DcPAR1 as an 476 antagonistic actor of PEL1. Indeed, the expression of AtPAR1 in carrots produces 477 orange embryo showing an early and positive effect of PAR1 on carotenoid 478 synthesis (Figure 1) but it did not generate an evident change in photomorphogenic 479 phenotype at the mature stage. 
Although AtPAR1 antisense produced elongated and hyper-etiolated plants (Zhou et al., 2014), carrot DcPAR1 antisense lines presented similar embryogenic and photomorphogenic development that control plants, especially in seedlings hypocotyl length (not shown), although they presented up to 95\% of DcPAR1 reduced expression. However, the consequences in the taproot of DcPAR1 antisense adult plants were drastic, showing a dramatic reduction in the size (thickness and length) and weight of the taproot in 4-month-old plants, a tendency that was maintained at 8 months of development. The phenotype obtained is partly reminiscent of that observed when silencing DCLCYB1, where the roots generated were thinner than the controls (Moreno et al., 2013) but less drastic than DcPAR1 antisense, showing a relevant role for DcPAR1 in carrot taproot development. Carrot root development has been previously reported to be closely related to carotenoid synthesis (Suslow et al., 1999; Clotault et al., 2008). Thus, it is possible that both processes are being regulated by similar factors at the transcriptional or post-transcriptional level. PAR1 seems to be a good candidate to participate in both processes. These results and those reported in Arabidopsis suggest that PAR1 has an important regulatory role on carotenoid synthesis and development. Considering that PAR1 is upstream of the pigment synthesis pathway, it has a broader functional role on the carotenoid synthesis in parallel with the regulation of root development in the absence of $\mathrm{W}$. AtPAR1 reduces hypocotyl elongation in

500 shade through the repression of auxin-induced genes such as SAUR15 and 501 SAUR68 likely through their ability to inhibit DNA binding of PIFs or other bHLH to 502 its binding motifs in the SAUR15 and SAUR68 promoters (Roig-Villanova et al., 503 2006, 2007; Bou-Torrent et al., 2008, 2015; Hao et al., 2012; Zhou et al., 2014).

504 Moreover, some of the phenotypes of AtPAR1 overexpressing lines are similar to 505 those reported in auxin, brassinosteroid or gibberellin mutants (Nakazawa y cols., 506 2001). Considering that DcPAR1 antisense lines present a short and thin taproot 507 with more lateral root abundance we propose that DcPAR1 may promote auxin 508 metabolism de-repression. Therefore, it remains to know if DcPAR1 could have a 509 role in hormone signaling during taproot development. 
510 Based on our results, we propose a simple model regarding DcPAR1 role in

511 carotenoid synthesis, plastid differentiation and taproot development (Figure 10).

512 Exposure of the orange carrot roots to light $(R / L)$ decreases DcPAR1 transcripts

513 levels which impairs the expression of carotenogenic genes such as DcPSYs. This

514 leads to a reduced amount of PSY protein accumulation, which in turn generated a

515 drop in total carotenoid accumulation with reduced $\alpha$-carotene and $\beta$-carotene

516 levels but an increase in lutein and chlorophylls. This might result in chloroplast

517 (rather than chromoplasts) differentiation and impairment in taproot development.

518 On the contrary, in roots grown underground (e.g., covered with soil; R/D), the

519 higher transcripts levels of DcPAR1 promotes an increment in DcPSYs expression

520 and PSY accumulation that leads to an increment in carotenoids synthesis

521 (specially $\alpha$-carotene and $\beta$-carotene) that would promote chromoplast

522 differentiation and secondary root development. Indeed, recently it was shown that

523 synthetically inducing a burst in the production of phytoene (the product of the PSY

524 enzymes and the first committed intermediate of the carotenoid pathway) elicits an

525 artificial chloroplast-to-chromoplast differentiation in leaves (Llorente et al., 2020).

526 Altogether, these results let us to propose that DcPAR1 is a key factor for

527 secondary root development, plastid differentiation and carotenoid synthesis in

528 carrot taproot grown underground.

\section{Conclusions:}

531 - DCPAR1, like its Arabidopsis counterpart AtPAR1, induces AtPSY expression,

532 boosts carotenoid synthesis and produces a dwarf phenotype when overexpressed

533 in A. thaliana.

534 - DCPAR1 positively regulates carotenoid synthesis and plastid differentiation in

535 carrot taproot grown underground.

536 - DcPAR1 is a key factor for carrot secondary root development. 


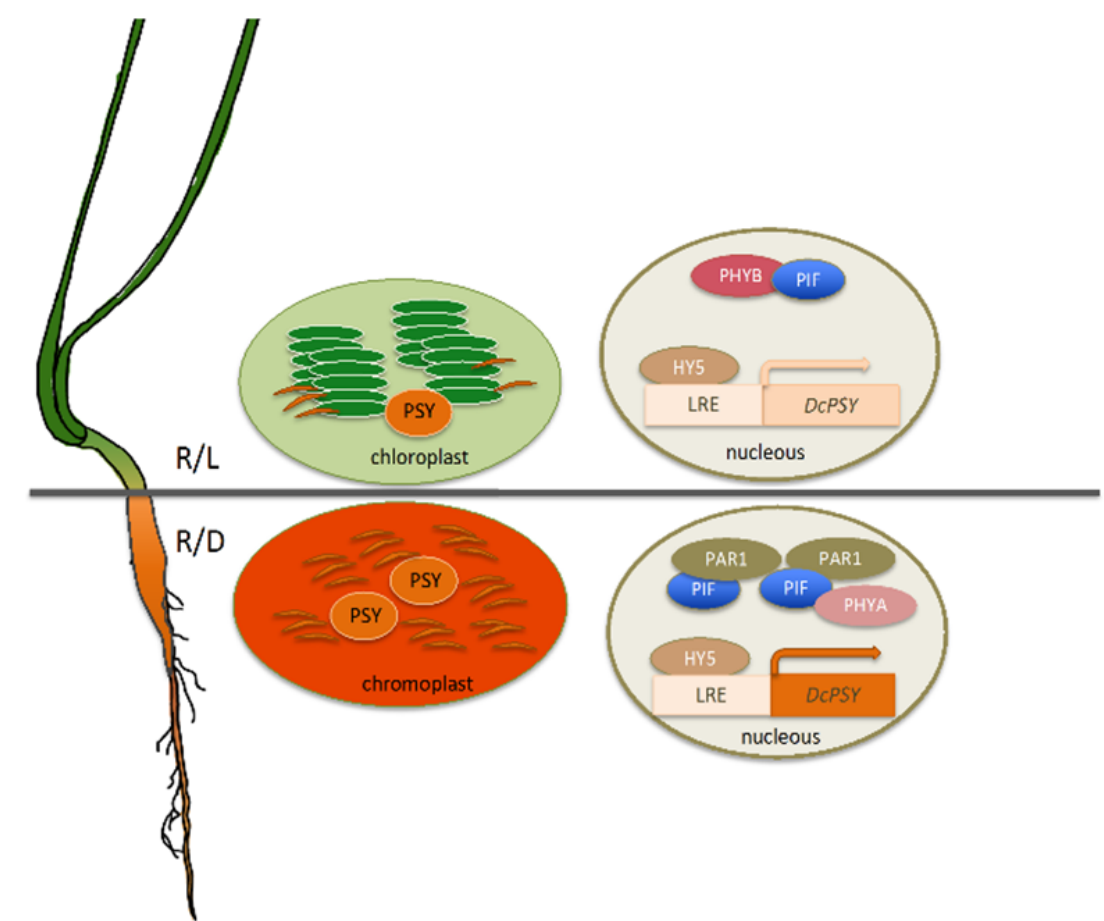

Figure 10: Proposed model depicting the role of DcPAR1 in carrot taproot development and accumulation of carotenoids. Roots grown exposed to W (R/L) presents a reduced expression of DcPAR1 which causes a decrease in the expression of carotenogenic genes such as DcPSYs, and in PSY protein accumulation. As a consequence, total carotenoids, $\alpha$-carotene and $\beta$-carotene accumulation drop but chlorophylls and lutein levels increase according to chloroplast differentiation. Taproot development is also impaired. On the contrary, in roots grown underground $(R / D)$, the enhance transcripts levels of DcPAR1 promotes an increment in DcPSYs expression and PSY accumulation that leads to an increment in carotenoids synthesis, chromoplast differentiation and secondary taproot development.

\section{Bioinformatic analysis}

542 NCBI platform was used to obtain the complete CDS of DcPAR1 using the contig 54342760 (202 bp) that corresponds to DcPAR1 and was obtained from the RNAseq 544 analysis (Arias et al, 2020). Conserved domain search analysis was performed 545 using the InterPro Scan (https://www.ebi.ac.uk/interpro/search/sequence-search) 546 and SMART (http://smart.embl-heidelberg.de/) in order to identify the bHLH 547 functional regions in DcPAR1.

DCPAR1 gene amplification and vector construction

551 The complete CDS sequence of PAR1 of Daucus carota var. Nantaise (363 pb 552 without stop codon) (NCBI access number XM_017390696.1) was amplified from 553 carrot taproot cDNA, using Herculase II Fusion DNA Polymerase (Agilent 554 technologies) and DcPAR1.F and DcPAR1.R primers (Supplementary Table I). 555 The sequence was cloned into the entry $\mathrm{PCR}^{\mathrm{TM}} 8 / \mathrm{GW} / \mathrm{TOPO}{ }^{\circledR}$ vector (Invitrogen) 
556 according to manufacturer's instructions and sequenced (Macrogen Corp, USA).

557 Clones of PCR8:DcPAR1 in sense and antisense orientation were recombined with

558 the destination vector pGWB5, obtaining the binary vectors pG5_35S:PAR1:GFP

559 (sense DcPAR1-GFP) and pG5_35S:PAR1as (antisense DcPAR1as) that were

560 used to overexpress and silence DcPAR1, respectively. The pBF1_35S:AtPAR1-

561 GFP binary vector was selected overexpress AtPAR1 as a fusion to the GFP

562 reporter gene (AtPAR1-GFP) and has been described elsewhere (Roig-Villanova

563 et al., 2007). All binary plasmids were transformed into Agrobacterium tumefaciens

564 strain GV3101 for stable Arabidopsis and carrot transformation.

565

566 Agrobacterium-mediated transformation of Daucus carota and Arabidopsis

567 thaliana.

568

569 Commercial seeds of Daucus carota var. Nantaise were surface-sterilized and 570 sown in culture medium MS (4.4 g/L MS salts (Murashige and Skoog, 1962), 20

$571 \mathrm{~g} / \mathrm{L}$ sucrose and 0,7\% agar) and grown in a culture chamber under $16 \mathrm{~h}$ long day 572 photoperiod at $23-25^{\circ} \mathrm{C}$. Plants of $10-20$ days post-germination were used for 573 Agrobacterium-mediated transformation as described in Gonzalez-Calquin and 574 Stange (2020). Briefly, the epicotyls of wild-type plants grown in vitro, were cut and 575 co-cultivated in presence of $A$. tumefaciens strain GV3101 carrying the DcPAR1576 GFP, DcPAR1as or AtPAR1:GFP vectors and placed on solidified MS in darkness. 577 After two days, the explants were transferred to MS culture medium supplemented 578 with $1 \mathrm{mg} / \mathrm{L}$ of 2,4-D, $50 \mathrm{mg} / \mathrm{L}$ of Hygromycin (for transgene selection) and 200 $579 \mathrm{mg} / \mathrm{L}$ of Timentin (for Agrobacterium control) for embryo development. After 4-5 580 weeks in darkness, the explants were transferred to MS culture medium 581 supplemented with $0.5 \mathrm{mg} / \mathrm{L}$ of 2,4-D, $100 \mathrm{mg} / \mathrm{L}$ of Hygromycin and $200 \mathrm{mg} / \mathrm{L}$ of 582 Timentin and grown in $\mathrm{W}$ (16 h long-day photoperiod at $23-25^{\circ} \mathrm{C}$ ) for 7 weeks 583 approximately. Finally, the hygromycin-resistant embryos were transferred to MS 584 culture medium without hormones to promote elongation of carrot seedlings. Plants 585 of $5-7 \mathrm{~cm}$ length were transferred to a mixture of soil: vermiculite (1:1) and 586 maintained under the same photoperiod and temperature conditions described 
587 above. Transgenic plants were selected by amplifying the respective transgen form

588 genomic DNA: AtPAR1 gene in the case of carrot plants transformed with 589 pBF1:AtPAR1:GFP (Bou-Torrent et al., 2015) with AtqPAR1.F and AtqPAR1.R 590 primers (Supplementary Table I), DcPAR1 gene in the case of Arabidopsis plants 591 using primers DcqPAR1.F and DcqPAR1.R (Supplementary Table I) or including 592 GFP amplification in the case of carrot plants transformed with pG5:PAR1as, using 593 primers DcPAR1.R and qEGFP.R (Supplementary Table I).

594 A. thaliana wild-type plants (Col-0 ecotype) were transformed using floral dip 595 (Zhang et al., 2006). Seeds were surface sterilized in a solution of sodium 596 hypochlorite $(50 \% \mathrm{v} / \mathrm{v})$ for $6 \mathrm{~min}$, washed three times with sterile water and sown in 597 solid MS medium (4.4 g/L MS salts, 0.44\% vitamins, 0.01\% myo-inositol and $0.7 \%$ 598 agar $\mathrm{pH} 5.8$ with or without selection). They were kept in a growth chamber with a $59916 \mathrm{~h}$ long day photoperiod illuminated with cool-white fluorescent light (115 $600 \mu \mathrm{mol} / \mathrm{m}^{2} \mathrm{~s}$ ) at $22^{\circ} \mathrm{C}$ for 2-6 weeks depending on the experimental assay. Selected 601 transgenic lines were transferred to a greenhouse in a mixture of soil:vermiculite 602 (1:1) for molecular analysis. The selection of T3 homozygous transgenic lines was 603 carried out by cultivation of selected transgenic T1, T2 and then T3 seeds in MS 604 medium with hygromycin $(15 \mu \mathrm{g} / \mathrm{ml})$ and selected those T3 with up to 95\% survival 605 for further molecular, biochemical and phenotypical analyses.

607 Pigments extraction and quantification

In carrot and Arabidopsis, carotenoid and chlorophyll extraction was carried out as 610 described previously (Simpson et al., 2016). Pigments were extracted from 20-100 $611 \mathrm{mg}$ of fresh carrot transgenic taproots and $100 \mathrm{mg}$ of entire 2 weeks-old 612 Arabidopsis T3 lines with $4 \mathrm{ml}$ of hexane:acetone:ethanol $(2: 1: 1 \mathrm{v} / \mathrm{v})$. After 613 centrifugation, the upper phase was recovered and dried with $\mathrm{N}_{2}$. For total 614 carotenoids and chlorophylls quantification, pigments were resuspended in $1 \mathrm{~mL}$ of 615 acetone and quantified in a spectrophotometer (Shimadzu) at 750, 662, 645 and $616474 \mathrm{~nm}$ in quartz cuvettes. Absorbance at 662, 645 and $474 \mathrm{~nm}$ permitted to 617 determine the concentration of chlorophyll $a$, chlorophyll $b$ and total carotenoids, 
618 respectively. The absorbance at $750 \mathrm{~nm}$ determines the turbidity of the sample

619 which may result in underestimation of the pigment concentration. Then, 620 concentration of chlorophyll a, chlorophyll b and total carotenoids was determined

621 as described previously (Lichtenthaler and Buschmann, 2001). Individual 622 carotenoids were quantified in a Shimadzu HPLC (LC-10AT) with a diode array 623 detector using a RP-18 Lichrocart 125-4 reverse phase column (Merck®) and a 624 mobile phase composed of acetonitrile:methanol:isopropanol (85:10:5 v/v). The 625 separation of carotenoids and chlorophyll pigments was carried out with a 1.5 $626 \mathrm{~mL} / \mathrm{min}$ flow rate, at room temperature and under isocratic conditions. The 627 identification of the pigments was performed as described by (Simpson et al., 628 2016).

RNA Extraction and Quantitative RT-PCR

632 RNA extraction was obtained from 20-100 mg of fresh carrot tap roots or leaves 633 and entire 2-weeks-old Arabidopsis plants that were pulverized with liquid nitrogen, 634 homogenized with CTAB buffer (2\% (w/v) CTAB, 2\% (w/v) PVP40, 25 mM EDTA, 2 $635 \mathrm{M} \mathrm{NaCl}, 100 \mathrm{mM}$ Tris- $\mathrm{HCl}(\mathrm{pH} \mathrm{8.0)}$ and $0.05 \%$ spermidine trihydrochloride) and 636 precipitated with $\mathrm{LiCl}(10 \mathrm{M})$ overnight. RNA was resuspended in nuclease-free 637 water and the genomic DNA traces were eliminated by a 40 min DNAse I treatment. 638 For cDNA synthesis, $3 \mu \mathrm{g}$ of total RNA was incubated with $1 \mathrm{mM}$ of Oligo-AP primer 639 (Supplementary Table I) and Improm II reverse transcriptase (Promega $\left.{ }^{\circ}\right)$ 640 according to the manufacturer's recommendations. Quantitative RT-PCR (qRT) 641 was performed as described in Fuentes et al. (2012) and Moreno et al. (2013) in a 642 Stratagene Mx3000P thermocycler, using SYBR Green double strand DNA binding 643 dye. AtqPAR1.F and AtqPAR1.R primers were used to amplify a specific fragment 644 of the coding sequences of AtPAR1 (AT2G42870) and DcqPAR1.F and 645 DcqPAR1.R for DcPAR1 (XM_017390696.1) (Supplementary Table I). DcqUbi.F 646 and DcqUbi.R primers were used to amplify Ubiquitin and AtqPP2A.F and 647 AtqPP2A.R to amplify PP2A housekeeping genes. Specific primers of 648 carotenogenic genes DcPSY1, DcPSY2, DCLCYB2, DCLCYE, DcCHXB1, 
649 DcCHXB2 and AtPSY were the same as described in Fuentes et al. (2012) and 650 summarized in Supplementary Table I. The qRT analysis was performed with three 651 biological replicates and two technical repeats and all reaction specificities were 652 tested with melting gradient dissociation curves. To test for significant differences 653 in gene expression, results were subjected to a one-way Anova $(p<0.05$, 654 confidence interval 95\%) with Dunnet post-test according to the General Linear 655 Models option in the statistical software package Graphpad Prism. The relative 656 transcript levels were obtained using the Pfaffl equation (Pfaffl, 2001).

Bimolecular fluorescence complementation (BiFC) Assay

660 The PCR8:DcPAR1 vector was recombined with BiFC vectors (Gateway ${ }^{\mathrm{TM}}$-based 661 BifC binary vectors, pYFC43 and pYFN43; Belda-Palazón et al., 2012), obtaining 662 N-YFP:DcPAR1 and C-YFP:DcPAR1. The BiFC binary vectors (Belda-Palazón et 663 al., 2012) and N-YFP:AtPIF7 and C-YFP:AtPIF7 vectors were provided by Dr. 664 Jaume Martínez-García (IBMCP CSIC-UPV, Valencia, Spain). The four vectors 665 were transformed in Agrobacterium GV3101 and used for Nicotiana benthamiana 666 agroinfiltration (Simpson et al., 2018). Four days after injection, YFP fluorescence 667 was detected under a LEICA TCS SP5 confocal microscope with a light excitation 668 wavelength of $488 \mathrm{~nm}$ and a filter for YFP at 520-560 nm. The images were 669 obtained and processed with Leica LAS AF Lite software.

\section{Arabidopsis protein extraction and western blot}

673 The Arabidopsis protein extraction was performed according to Saucedo et al. 674 (2019) with modifications. Briefly, $400 \mathrm{mg}$ of fresh tissue of entire 2-weeks-old 675 Arabidopsis plants were pulverized with liquid nitrogen and then $4 \mathrm{ml}$ of extraction 676 buffer [0.5 M TrisHCl pH8, 0.7 M Sucrose, 2 protease inhibitor tablets (complete 677 Mini, EDTA-free- Thermo Scientific Lot \# UG27666820), 50 mM EDTA, KCl 0.1 M, $678 \beta$-mercaptoethanol 0.2\%)] were added and homogenized until the sample was 679 completely thawed. Then, $2 \mathrm{ml}$ of basic saturated phenol pH 8.0 (Winkler \# 
20192088) were added, shaken 10 minutes in ice and centrifuged at $8000 \mathrm{~g}$ for 19 min at $4{ }^{\circ} \mathrm{C}$. The supernatant was recovered and four volumes of $0.1 \mathrm{M}$ ammonium

682 acetate in methanol (Merck gradient for liquid chromatography) were added, and 683 proteins were precipitate overnight at $-20^{\circ} \mathrm{C}$. After centrifugation the pellet was 684 washed with $0.1 \mathrm{M}$ ammonium acetate in methanol, and with acetone. The 685 remaining acetone was evaporated at room temperature and the proteins (pellet) were stored at $-20{ }^{\circ} \mathrm{C}$ in resuspension buffer (100 mM Tris- $\mathrm{HCl} \mathrm{pH} \mathrm{7.0,1 \%} \mathrm{SDS).}$ The extraction was carried out in triplicate for each transgenic line and control.

Figure legends

Figure 1. Molecular and biochemical analysis of AtPAR1 transgenic carrots.

693 (A) In vitro regeneration of carrot transformant plants. Embryo regeneration stage 694 is shown (18-20 weeks after explants transformation). The arrow indicates orange 695 embryos that later gives rise to whole carrot plants in wild-type (WT), AtPAR1 696 (AtPAR1:GFP) and DcPAR1as. Scale bar: $5 \mathrm{~mm}$. (B) Real time expression of 697 AtPAR1, DCPSY1 and DCPSY2 in transgenic (OE1, OE2, OE5 and OE6) and wild698 type (WT) carrot taproots. Ubiquitin was used as housekeeping gene. (C) Total 699 carotenoids, $\beta$-carotene and $\alpha$-carotene levels in transgenic (OE1, OE2, OE5 and 700 OE6) and WT carrot taproots. Letters and asterisks indicate significant differences 701 between WT and transgenic lines (one-way ANOVA analysis with Dunnet post-test; $\left.{ }^{* * * *} p<0.0001,{ }^{* * *} p<0.001,{ }^{* *} p<0.01,{ }^{*} p<0.1\right)$

Figure 2. DcPAR1 and AtPAR1 protein alignment. (A) The predicted bHLH

705 domains are highlighted in two shades of gray. The red box delimits the basic 706 domains, and blue, green and yellow boxes mark the helix 1, the loop and the helix 7072 subdomains, respectively. (B) Alignment of AtPAR1 and DcPAR1 bHLH domains.

708 The upper boxes indicate the subdomain extensions based in Heim et al. (2003) 709 and Roig-Villanova et al. (2007). Diamonds highlight residues 5, 9 and 13 (Asp, 710 Glu and Lys, respectively), the conserved leucine residue at position 23 in helix 1 
711 and additional conserved residues in helix 2. Different and identical amino acids

712 are highlighted in each subdomain. All alignments were performed with Clustal 713 Omega.

715 Figure 3. Interaction in vivo between DcPAR1 and AtPIF7. Bimolecular 716 Fluorescence Complementation (BiFC) assay between DcPAR1 and AtPIF7 is 717 shown. The NY-AtPIF7/DcPAR1 corresponds to AtPIF7 or DcPAR1 genes cloned 718 in fusion to $\mathrm{N}$-terminal region of YFP gene (NY) and CY-AtPIF7/DcPAR1 719 corresponds to the same genes cloned in fusion to the C-terminal region of YFP 720 gene (CY). The NY and CY are empty vectors. Nicotiana benthamiana (tobacco) 721 leaves were co-infiltrated with the NY-and CY-derived plasmids to express the 722 indicated fusion proteins. The top row shows the fluorescence of reconstituted YFP 723 (indicative of a positive interaction of $\mathrm{YN}$ and $\mathrm{YC}$ fusions), the middle row shows 724 the bright filed of the same area and the bottom row shows the merge of previous 725 conditions. Scale bar: $50 \mu \mathrm{m}$ Figure 4: Expression and carotenoid quantification of transgenic Arabidopsis 728 lines overexpressing DcPAR1. (A) Relative expression level of DcPAR1, AtPAR1 729 and AtPSY in two-week-old 35S:DcPAR1-GFP (L1, L2, L3, L4) transgenic lines.

730 The relative expression levels were normalized to housekeeping EFf1A4. (B) 731 Western blot of DcPAR1-GFP, AtPSY and Actin in the transgenic Arabidopsis lines 732 indicated in A using antiGFP, antiPSY and anti-ACTIN antibodies. Graphs present 733 the semi-quantification of DcPAR1-GFP and AtPSY from Western blot using Actin 734 abundance as normalizer. Each graph shows the average of three biological 735 replicates. ImageJ program was used for WB semi quantification. MW: molecular 736 weight; Col-0: wild type plants; L1-L4: transgenic plants. (C) Total carotenoid 737 content in two-weeks-old Col-0 and transgenic plants. Concentration is presented 738 in $\mu \mathrm{g} / \mathrm{g}$ of dry weight (DW). Asterisks indicate significant differences between WT 739 and transgenic plants performed by one-way ANOVA analysis with Dunnet post740 test; ${ }^{* * *} p<0.0001,{ }^{* * *} p<0.001,{ }^{* *} p<0.01,{ }^{*} p<0.1$. 
742 Figure 5: Phenotype of mature transgenic Arabidopsis lines overexpressing

743 DcPAR1. (A) Picture showing the length and phenotype of representative six-

744 weeks-old plants of Col-0 and T3 transgenic lines. (B) Stem and (C) Silique length

745 of six-week-old Col-0 and T3 transgenic plants. Each value is the mean \pm SE/SD of

7465 plants each and using ImageJ program. Asterisks indicate significant differences

747 between WT and transgenic plants performed by one-way ANOVA analysis with

748 Dunnet post-test; ${ }^{* * * *} p<0.0001,{ }^{* * *} p<0.001,{ }^{* *} p<0.01,{ }^{*} p<0.1$.

750 Figure 6: Phenotype and expression analysis of four-months-old DcPAR1as

751 transgenic carrot taproots. (A) Relative expression level of DcPAR1 in AS1, 752 AS5, AS6 and AS10 transgenics lines. (B) Representative phenotype of a WT and 753 a DcPAR1as transgenic carrot root (line AS10) grown four months underground 754 after transplanting. Bar: $1 \mathrm{~cm}$. (C) Relative expression level of DcPSY1, DcPSY2, 755 DCLCYB2, DCLCYE DCCHXB1 and DCCHXB2. The relative expression was carried 756 out in triplicate (two technical replicas each) and normalized to the housekeeping 757 Ubiquitin gene. WT was used as calibrator. Asterisks indicate significant 758 differences between transgenic lines and WT plant determined by one-way 759 ANOVA analysis with Dunnet post-test; ${ }^{* * *} p<0.0001,{ }^{* * *} p<0.001,{ }^{* *} p<0.01,{ }^{*}$ $760 \quad \mathrm{p}<0.1$.

762 Figure 7: Total and individual carotenoid content in four-month-old 763 DcPAR1as carrot taproots. (A) lutein, $\alpha$-carotene and $\beta$-carotene levels was 764 determined by HPLC-RP and (B) total carotenoids were quantified in a 765 spectrophotometer at $474 \mathrm{~nm}$. The pigment content is indicated in $\mu \mathrm{g} / \mathrm{g}$ of dry 766 weight (DW) and was measured in triplicate. Asterisks indicate significant

767 differences between transgenic lines and WT plant determined by one-way 768 ANOVA analysis with Dunnet post-test; ${ }^{* * *} p<0.0001,{ }^{* * *} p<0.001,{ }^{* *} p<0.01,{ }^{*}$ $769 p<0.1$

771 Figure 8: Phenotype and expression analysis of eights-months-old 772 DcPAR1as transgenic carrot taproots. (A) Representative phenotype of carrot 
773 taproots of a WT and AS1, AS5 and AS6 DcPAR1as transgenic plants grown eight

774 months underground after transplanting (line AS10 was harvested at four months

775 and not shown in here). Bar: $1 \mathrm{~cm}$. Graph in the right shows the relative expression

776 level of DCPAR1 in the indicated lines. (B) Relative expression level of DcPSY1,

777 DCPSY2, DCLCYB2, DCLCYE, DcCHXB1 and DCCHXB2. Relative expression was

778 carried out in triplicate (two technical replicas each) and normalized to the

779 housekeeping Ubiquitin gene. Asterisks indicate significant differences between

780 transgenic lines and WT plant determined by one-way ANOVA analysis with

781 Dunnet post-test; ${ }^{* * * *} p<0.0001,{ }^{* * *} p<0.001,{ }^{* *} p<0.01,{ }^{*} p<0.1$

782

783 Figure 9: Carotenoids and chlorophylls content in eight-months-old

784 DcPAR1as transgenic carrot taproots. (A) Total carotenoids levels and (B)

785 cholorophyll $a$ and $b$ in carrot taproots of WT and AS1, AS5 and AS6 DcPAR1as

786 transgenic plants. (C) Lutein, $\alpha$-carotene and $\beta$-carotene levels was determined by

787 HPLC-RP. Pigment content is indicated in $\mu \mathrm{g} / \mathrm{g}$ of dry weight (DW) and was

788 measured in triplicate. Asterisks indicate significant differences between transgenic

789 lines and WT plant determined by one-way ANOVA analysis with Sidak post-test;

$790{ }^{* * * *} p<0.0001,{ }^{* * *} p<0.001,{ }^{* *} p<0.01,{ }^{*} p<0.1$

791

792 Figure 10: Proposed model depicting the role of DcPAR1 in carrot taproot

793 development and accumulation of carotenoids. Roots grown exposed to W

$794(\mathrm{R} / \mathrm{L})$ presents a reduced expression of DcPAR1 which causes a decrease in the

795 expression of carotenogenic genes such as DcPSYs, and in PSY protein

796 accumulation. As a consequence, total carotenoids, $\alpha$-carotene and $\beta$-carotene

797 accumulation drop but chlorophylls and lutein levels increase according to

798 chloroplast differentiation. Taproot development is also impaired. On the contrary,

799 in roots grown underground (R/D), the enhance transcripts levels of DcPAR1

800 promotes an increment in DcPSYs expression and PSY accumulation that leads to

801 an increment in carotenoids synthesis, chromoplast differentiation and secondary

802 taproot development.

803 
bioRxiv preprint doi: https://doi.org/10.1101/2021.09.22.461395; this version posted September 24, 2021. The copyright holder for this preprint (which was not certified by peer review) is the author/funder. All rights reserved. No reuse allowed without permission.

\section{4}

805 


\section{Parsed Citations}

Adams-Phillips, L., Barry, C., and Giovannoni, J. (2004). Signal transduction systems regulating fruit ripening. Trends Plant Sci. 9. doi:10.1016/j.tplants.2004.05.004.

Google Scholar: Author Only Title Only Author and Title

Arias, D., Maldonado, J., Silva, H., and Stange, C. (2020). Ade novo transcriptome analysis revealed that photomorphogenic genes are required for carotenoid synthesis in the dark-grown carrot taproot. Mol. Genet. Genomics 295. doi:10.1007/s00438-020-01707-4.

Google Scholar: Author Only Title Only Author and Title

Bae, G., and Choi, G. (2008). Decoding of light signals by plant phytochromes and their interacting proteins. Annu. Rev. Plant Biol. 59. doi:10.1146/annurev.arplant.59.032607.092859.

Google Scholar: Author Only Title Only Author and Title

Ballaré, C. L., and Pierik, R. (2017). The shade-avoidance syndrome: Multiple signals and ecological consequences. Plant Cell Environ. 40. doi:10.1111/pce.12914.

Google Scholar: Author Only Title Only Author and Title

Belda-Palazón, B., Ruiz, L., Martí, E., Tárraga, S., Tiburcio, A F., Culiáñez, F., et al. (2012). Aminopropyltransferases Involved in Polyamine Biosynthesis Localize Preferentially in the Nucleus of Plant Cells. PLoS One 7. doi:10.1371/journal.pone.0046907.

Google Scholar: Author Only Title Only Author and Title

Bou-Torrent, J., Roig-Villanova, I., Galstyan, A, and Martínez-García, J. F. (2008). PAR1 and PAR2 integrate shade and hormone transcriptional networks. Plant Signal. Behav. 3. doi:10.4161/psb.3.7.5599.

Google Scholar: Author Only Title Only Author and Title

Bou-Torrent, J., Toledo-Ortiz, G., Ortiz-Alcaide, M., Cifuentes-Esquivel, N., Halliday, K. J., Martinez-García, J. F., et al. (2015).

Regulation of carotenoid biosynthesis by shade relies on specific subsets of antagonistic transcription factors and cofactors. Plant

Physiol. 169. doi:10.1104/pp.15.00552.

Google Scholar: Author Only Title Only Author and Title

Bramley, P. M. (2002). Regulation of carotenoid formation during tomato fruit ripening and development. J. Exp. Bot. 53.

doi:10.1093/jxb/erf059.

Google Scholar: Author Only Title Only Author and Title

Cifuentes-Esquivel, N., Bou-Torrent, J., Galstyan, A, Gallemí, M., Sessa, G., Salla Martret, M., et al. (2013). The bHLH proteins BEE and BIM positively modulate the shade avoidance syndrome in Arabidopsis seedlings. Plant J. 75. doi:10.1111/tpj.12264.

Google Scholar: Author Only Title Only Author and Title

Clotault, J., Peltier, D., Berruyer, R., Thomas, M., Briard, M., and Geoffriau, E. (2008). Expression of carotenoid biosynthesis genes during carrot root development. J. Exp. Bot. 59, 3563-3573. doi:10.1093/jxb/ern210.

Google Scholar: Author Only Title Only Author and Title

De Wit, M., Galvão, V. C., and Fankhauser, C. (2016). Light-Mediated Hormonal Regulation of Plant Growth and Development. Annu.

Rev. Plant Biol. 67. doi:10.1146/annurev-arplant-043015-112252.

Google Scholar: Author Only Title Only Author and Title

Fernández-Milmanda, G. L., and Ballaré, C. L. (2021). Shade Avoidance: Expanding the Color and Hormone Palette. Trends Plant Sci. 26. doi:10.1016/j.tplants.2020.12.006.

Google Scholar: Author Only Title Only Author and Title

Fiorucci, A S., Galvão, V. C., Ince, Y. Ç., Boccaccini, A, Goyal, A, Alenbach Petrolati, L., et al. (2020). PHYTOCHROME INTERACTING FACTOR 7 is important for early responses to elevated temperature in Arabidopsis seedlings. New Phytol. 226. doi:10.1111/nph.16316. Google Scholar: Author Only Title Only Author and Title

Fuentes, P., Pizarro, L., Moreno, J. C., Handford, M., Rodriguez-Concepcion, M., and Stange, C. (2012). Light-dependent changes in plastid differentiation influence carotenoid gene expression and accumulation in carrot roots. Plant Mol. Biol. 79, 47-59.

doi:10.1007/s11103-012-9893-2.

Google Scholar: Author Only Title Only Author and Title

Galstyan, A, Bou-Torrent, J., Roig-Villanova, l., and Martínez-García, J. F. (2012). A dual mechanism controls nuclear localization in the atypical basic-helix-loop-helix protein PAR1 of Arabidopsis thaliana. Mol. Plant 5. doi:10.1093/mp/sss006.

Google Scholar: Author Only Title Only Author and Title

Galstyan, A, Cifuentes-Esquivel, N., Bou-Torrent, J., and Martinez-Garcia, J. F. (2011). The shade avoidance syndrome in Arabidopsis: A fundamental role for atypical basic helix-loop-helix proteins as transcriptional cofactors. Plant J. 66. doi:10.1111/j.1365-

313X.2011.04485.X.

Google Scholar: Author Only Title Only Author and Title

Giovannoni, J. J. (2004). Genetic regulation of fruit development and ripening. Plant Cell 16. doi:10.1105/tpc.019158.

Google Scholar: Author Only Title Only Author and Title

Gonzalez-Calquin, C., and Stange, C. (2020). Agrobacterium tumefaciens-Mediated Stable Transformation of Daucus carota. Methods 
Mol. Biol. 2083. doi:10.1007/978-1-4939-9952-1_24.

Google Scholar: Author Only Title Only Author and Title

Hao, Y., Oh, E., Choi, G., Liang, Z, and Wang, Z Y. (2012). Interactions between HLH and bHLH factors modulate light-regulated plant development. Mol. Plant 5. doi:10.1093/mp/sss011.

Google Scholar: Author Only Title Only Author and Title

Heim, M. A, Jakoby, M., Werber, M., Martin, C., Weisshaar, B., and Bailey, P. C. (2003). The basic helix-loop-helix transcription factor family in plants: Agenome-wide study of protein structure and functional diversity. Mol. Biol. Evol. 20. doi:10.1093/molbev/msg088.

Google Scholar: Author Only Title Only Author and Title

Hirschberg, J. (2001). Carotenoid biosynthesis in flowering plants. Curr. Opin. Plant Biol. 4. doi:10.1016/S1369-5266(00)00163-1.

Google Scholar: Author Only Title Only Author and Title

Hornitschek, P., Kohnen, M. V., Lorrain, S., Rougemont, J., Ljung, K., López-Vidriero, l., et al. (2012). Phytochrome interacting factors 4 and 5 control seedling growth in changing light conditions by directly controlling auxin signaling. Plant J. 71. doi:10.1111/j.1365-

313X.2012.05033.X.

Google Scholar: Author Only Title Only Author and Title

Howitt, C. A, and Pogson, B. J. (2006). Carotenoid accumulation and function in seeds and non-green tissues. Plant, Cell Environ. 29. doi:10.1111/j.1365-3040.2005.01492.x.

Google Scholar: Author Only Title Only Author and Title

Iorizzo, M., Ellison, S., Senalik, D., Zeng, P., Satapoomin, P., Huang, J., et al. (2016). A high-quality carrot genome assembly provides new insights into carotenoid accumulation and asterid genome evolution. Nat. Genet. 48. doi:10.1038/ng.3565.

Google Scholar: Author Only Title Only Author and Title

Kami, C., Lorrain, S., Hornitschek, P., and Fankhauser, C. (2010). "Light-regulated plant growth and development," in Current Topics in Developmental Biology doi:10.1016/S0070-2153(10)91002-8.

Google Scholar: Author Only Title Only Author and Title

Leivar, P., Monte, E., Oka, Y., Liu, T., Carle, C., Castillon, A, et al. (2008). Multiple Phytochrome-Interacting bHLH Transcription Factors Repress Premature Seedling Photomorphogenesis in Darkness. Curr. Biol. 18. doi:10.1016/j.cub.2008.10.058.

Google Scholar: Author Only Title Only Author and Title

Leivar, P., Tepperman, J. M., Monte, E., Calderon, R. H., Liu, T. L., and Quail, P. H. (2009). Definition of early transcriptional circuitry involved in light-induced reversal of PIF-imposed repression of photomorphogenesis in young Arabidopsis seedlings. Plant Cell 21. doi:10.1105/tpc.109.070672.

Google Scholar: Author Only Title Only Author and Title

Li, L., Ljung, K., Breton, G., Schmitz, R. J., Pruneda-Paz, J., Cowing-Ztron, C., et al. (2012). Linking photoreceptor excitation to changes in plant architecture. Genes Dev. 26. doi:10.1101/gad.187849.112.

Google Scholar: Author Only Title Only Author and Title

Lichtenthaler, H. K., and Buschmann, C. (2001). Extraction of Phtosynthetic Tissues:Chlorophylls and Carotenoids. Curr. Protoc. Food Anal. Chem 1. doi:10.1002/0471142913.faf0402s01.

Google Scholar: Author Only Title Only Author and Title

Llorente, B., Martinez-Garcia, J. F., Stange, C., and Rodriguez-Concepcion, M. (2017). Illuminating colors: regulation of carotenoid biosynthesis and accumulation by light. Curr. Opin. Plant Biol. 37. doi:10.1016/j.pbi.2017.03.011.

Google Scholar: Author Only Title Only Author and Title

Llorente, B., Torres-Montilla, S., Morelli, L., Florez-Sarasa, I., Matus, J. T., Ezquerro, M., et al. (2020). Synthetic conversion of leaf chloroplasts into carotenoid-rich plastids reveals mechanistic basis of natural chromoplast development. Proc. Natl. Acad. Sci. U. S. A 117. doi:10.1073/pnas.2004405117.

Google Scholar: Author Only Title Only Author and Title

Lorrain, S., Alen, T., Duek, P. D., Whitelam, G. C., and Fankhauser, C. (2008). Phytochrome-mediated inhibition of shade avoidance involves degradation of growth-promoting bHLH transcription factors. Plant J. 53. doi:10.1111/j.1365-313X.2007.03341.X.

Google Scholar: Author Only Title Only Author and Title

Maass, D., Arango, J., Wüst, F., Beyer, P., and Welsch, R. (2009). Carotenoid crystal formation in Arabidopsis and carrot roots caused by increased phytoene synthase protein levels. PLoS One 4. doi:10.1371/journal.pone.0006373.

Google Scholar: Author Only Title Only Author and Title

Moreno, J. C., Pizarro, L., Fuentes, P., Handford, M., Cifuentes, V., and Stange, C. (2013). Levels of Lycopene $\beta$-Cyclase 1 Modulate Carotenoid Gene Expression and Accumulation in Daucus carota. PLoS One 8. doi:10.1371/journal.pone.0058144.

Google Scholar: Author Only Title Only Author and Title

Nakazawa, M., Yabe, N., Ichikawa, T., Yamamoto, Y.Y., Yoshizumi, T., Hasunuma, K., and Matsui, M. (2001). DFL1, an auxin-responsive GH3 gene homologue, negatively regulates shoot cell elongation and lateral root formation, and positively regulates the light response of hypocotyl length. Plant J 25: 213 - 221. doi.org/10.1046/j.1365-313x.2001.00957.x

Google Scholar: Author Only Title Only Author and Title 
Paulišić, S., Qin, W., Arora Verasztó, H., Then, C., Alary, B., Nogue, F., et al. (2021). Adjustment of the PIF7-HFR1 transcriptional module activity controls plant shade adaptation. EMBO J. 40. doi:10.15252/embj.2019104273.

Google Scholar: Author Only Title Only Author and Title

Pfaffl, M. W. (2001). Anew mathematical model for relative quantification in real-time RT-PCR. Nucleic Acids Res. 29. doi:10.1093/nar/29.9.e45.

Google Scholar: Author Only Title Only Author and Title

Pham, V. N., Kathare, P. K., and Huq, E. (2018). Phytochromes and phytochrome interacting factors. Plant Physiol. 176. doi:10.1104/pp.17.01384.

Google Scholar: Author Only Title Only Author and Title

Quail, P. H. (2002). Phytochrome photosensory signalling networks. Nat. Rev. Mol. Cell Biol. 3. doi:10.1038/nrm728.

Google Scholar: Author Only Title Only Author and Title

Quian-Ulloa, R., and Stange, C. (2021). Carotenoid biosynthesis and plastid development in plants: The role of light. Int. J. Mol. Sci. 22. doi:10.3390/ijms22031184.

Google Scholar: Author Only Title Only Author and Title

Rodríguez-Concepción, M. (2010). Supply of precursors for carotenoid biosynthesis in plants. Arch. Biochem Biophys. 504. doi:10.1016/j.abb.2010.06.016.

Google Scholar: Author Only Title Only Author and Title

Rodriguez-Concepcion, M., and Stange, C. (2013). Biosynthesis of carotenoids in carrot: An underground story comes to light. Arch. Biochem Biophys. 539. doi:10.1016/j.abb.2013.07.009.

Google Scholar: Author Only Title Only Author and Title

Rodríguez-Villalón, A, Gas, E., and Rodríguez-Concepción, M. (2009). Phytoene synthase activity controls the biosynthesis of carotenoids and the supply of their metabolic precursors in dark-grown Arabidopsis seedlings. Plant J. 60. doi:10.1111/j.1365313X.2009.03966.X.

Google Scholar: Author Only Title Only Author and Title

Roig-Villanova, I., Bou-Torrent, J., Galstyan, A, Carretero-Paulet, L., Portolés, S., Rodríguez-Concepción, M., et al. (2007). Interaction of shade avoidance and auxin responses: Arole for two novel atypical bHLH proteins. EMBO J. 26. doi:10.1038/sj.emboj.7601890.

Google Scholar: Author Only Title Only Author and Title

Roig-Villanova, I., Bou, J., Sorin, C., Devlin, P. F., and Martínez-García, J. F. (2006). Identification of primary target genes of phytochrome signaling. Early transcriptional control during shade avoidance responses in arabidopsis. Plant Physiol. 141. doi:10.1104/pp.105.076331.

Google Scholar: Author Only Title Only Author and Title

Ronen, G., Cohen, M., Zamir, D., and Hirschberg, J. (1999). Regulation of carotenoid biosynthesis during tomato fruit development: Expression of the gene for lycopene epsilon-cyclase is down-regulated during ripening and is elevated in the mutant Delta. Plant $\mathrm{J}$. 17. doi:10.1046/j.1365-313X.1999.00381.x.

Google Scholar: Author Only Title Only Author and Title

Rosas-Saavedra, C., and Stange, C. (2016). Biosynthesis of carotenoids in plants: Enzymes and color. Subcell. Biochem 79. doi:10.1007/978-3-319-39126-7_2.

Google Scholar: Author Only Title Only Author and Title

Ruyter-Spira, C., A-Babili, S., Krol, S. van der, and Bouwmeester, H. (2013). The biology of strigolactones. Trends Plant Sci 18 , 72-83. doi:10.1016/j.tplants.2012.10.003.

Google Scholar: Author Only Title Only Author and Title

Sandmann, G. (2015). Carotenoids of biotechnological importance. Adv. Biochem Eng. Biotechnol. 148. doi:10.1007/10_2014_277. Google Scholar: Author Only Title Only Author and Title

Sandmann, G., Römer, S., and Fraser, P. D. (2006). Understanding carotenoid metabolism as a necessity for genetic engineering of crop plants. Metab. Eng. 8. doi:10.1016/j.ymben.2006.01.005.

Google Scholar: Author Only Title Only Author and Title

Saucedo, S., González, A, Gómez, M., Contreras, R. A, Laporte, D., Sáez, C. A, et al. (2019). Oligo-carrageenan kappa increases glucose, trehalose and TOR-P and subsequently stimulates the expression of genes involved in photosynthesis, and basal and secondary metabolisms in Eucalyptus globulus. BMC Plant Biol. 19. doi:10.1186/s12870-019-1858-z.

Google Scholar: Author Only Title Only Author and Title

Shen, H., Zhu, L., Castillon, A, Majee, M., Downie, B., and Huq, E. (2008). Light-induced phosphorylation and degradation of the negative regulator phytochrome-interacting factor1 from Arabidopsis depend upon its direct physical interactions with photoactivated phytochromes. Plant Cell 20. doi:10.1105/tpc.108.060020.

Google Scholar: Author Only Title Only Author and Title

Shin, J., Kim, K., Kang, H., Zulfugarov, I. S., Bae, G., Lee, C. H., et al. (2009). Phytochromes promote seedling light responses by inhibiting four negatively-acting phytochrome-interacting factors. Proc. Natl. Acad. Sci. U. S. A 106. doi:10.1073/pnas.0812219106. 
Google Scholar: Author Only Title Only Author and Title

Simkin, A J., Zhu, C., Kuntz, M., and Sandmann, G. (2003). Light-dark regulation of carotenoid biosynthesis in pepper (Capsicum annuum) leaves. J. Plant Physiol. 160. doi:10.1078/0176-1617-00871.

Google Scholar: Author Only Title Only Author and Title

Simpson, K., Cerda, A, and Stange, C. (2016a). Carotenoid biosynthesis in daucus carota. Subcell. Biochem 79. doi:10.1007/978-3-31939126-7_7.

Google Scholar: Author Only Title Only Author and Title

Simpson, K., Fuentes, P., Quiroz-Iturra, L. F., Flores-Ortiz, C., Contreras, R., Handford, M., et al. (2018). Unraveling the induction of phytoene synthase 2 expression by salt stress and abscisic acid in Daucus carota. J. Exp. Bot. 69, 4113-4126. doi:10.1093/jxb/ery207.

Google Scholar: Author Only Title Only Author and Title

Simpson, K., Quiroz, L. F., Rodriguez-Concepción, M., and Stange, C. R. (2016b). Differential contribution of the first two enzymes of the MEP pathway to the supply of metabolic precursors for carotenoid and chlorophyll biosynthesis in carrot (Daucus carota). Front. Plant Sci. 7. doi:10.3389/fpls.2016.01344.

Google Scholar: Author Only Title Only Author and Title

Stange, C., and Flores, C. (2012). "Carotenoids and Photosynthesis - Regulation of Carotenoid Biosyntesis by Photoreceptors," in Advances in Photosynthesis - Fundamental Aspects doi:10.5772/29161.

Google Scholar: Author Only Title Only Author and Title

Stange, C., Fuentes, P., Handford, M., and Pizarro, L. (2008). Daucus carota as a novel model to evaluate the effect of light on carotenogenic gene expression. Biol. Res. 41. doi:10.4067/S0716-97602008000300006.

Google Scholar: Author Only Title Only Author and Title

Stanley, L., and Yuan, Y. W. (2019). Transcriptional Regulation of Carotenoid Biosynthesis in Plants: So Many Regulators, So Little Consensus. Front. Plant Sci. 10. doi:10.3389/fpls.2019.01017.

Google Scholar: Author Only Title Only Author and Title

Suslow, T. V., Wu, J., and Peiser, G. (1999). "Characterization of carotenoid composition of carrots affected by 'light root syndrome,"' in Integrated View of Fruit and Vegetable Quality doi:10.1201/9781351073769.

Google Scholar: Author Only Title Only Author and Title

Toledo-Ortiz, G., Huq, E., and Rodríguez-Concepción, M. (2010). Direct regulation of phytoene synthase gene expression and carotenoid biosynthesis by phytochrome-interacting factors. Proc. Natl. Acad. Sci. U. S. A 107. doi:10.1073/pnas.0914428107. Google Scholar: Author Only Title Only Author and Title

Tripathi, S., Hoang, Q. T. N., Han, Y. J., and Kim, J. II (2019). Regulation of photomorphogenic development by plant phytochromes. Int. J. Mol. Sci. 20. doi:10.3390/ijms20246165.

Google Scholar: Author Only Title Only Author and Title

Von Lintig, J., Welsch, R., Bonk, M., Giuliano, G., Batschauer, A, and Kleinig, H. (1997). Light-dependent regulation of carotenoid biosynthesis occurs at the level of phytoene synthase expression and is mediated by phytochrome in Sinapis alba and Arabidopsis thaliana seedlings. Plant J. 12. doi:10.1046/j.1365-313X.1997.d01-16.x.

Google Scholar: Author Only Title Only Author and Title

Woitsch, S., and Römer, S. (2003). Expression of xanthophyll biosynthetic genes during light-dependent chloroplast differentiation. Plant Physiol. 132. doi:10.1104/pp.102.019364.

Google Scholar: Author Only Title Only Author and Title

Zhang, X., Henriques, R., Lin, S. S., Niu, Q. W., and Chua, N. H. (2006). Agrobacterium-mediated transformation of Arabidopsis thaliana using the floral dip method. Nat. Protoc. 1. doi:10.1038/nprot.2006.97.

Google Scholar: Author Only Title Only Author and Title

Zhou, P., Song, M., Yang, Q., Su, L., Hou, P., Guo, L., et al. (2014). Both PHYTOCHROME RAPIDLY REGULATED1 (PAR1) and PAR2 promote seedling photomorphogenesis in multiple light signaling pathways. Plant Physiol. 164. doi:10.1104/pp.113.227231.

Google Scholar: Author Only Title Only Author and Title 